\title{
The Central Role of Glia in Pathological Pain and the Potential of Targeting the Cannabinoid 2 Receptor for Pain Relief
}

\author{
Jenny L. Wilkerson and Erin D. Milligan \\ Department of Neurosciences, School of Medicine, University of New Mexico, HSC, MSC08-4740, Albuquerque, NM 87131, USA \\ Correspondence should be addressed to Jenny L. Wilkerson, jlwilkerson@salud.unm.edu
}

Received 17 August 2011; Accepted 17 September 2011

Academic Editor: J. H. Abraini

Copyright ( $) 2011$ J. L. Wilkerson and E. D. Milligan. This is an open access article distributed under the Creative Commons Attribution License, which permits unrestricted use, distribution, and reproduction in any medium, provided the original work is properly cited.

\begin{abstract}
Under normal conditions, acute pain processing consists of well-characterized neuronal signaling events. When dysfunctional pain signaling occurs, pathological pain ensues. Glial activation and their released factors participate in the mediation of pathological pain. The use of cannabinoid compounds for pain relief is currently an area of great interest for both basic scientists and physicians. These compounds, bind mainly either the cannabinoid receptor subtype $1\left(\mathrm{CB}_{1} \mathrm{R}\right)$ or cannabinoid receptor subtype $2\left(\mathrm{CB}_{2} \mathrm{R}\right)$ and are able to modulate pain. Although cannabinoids were initially only thought to modulate pain via neuronal mechanisms within the central nervous system, strong evidence now supports that $\mathrm{CB}_{2} \mathrm{R}$ cannabinoid compounds are capable of modulating glia, (e.g. astrocytes and microglia) for pain relief. However, the mechanisms underlying cannabinoid receptor-mediated pain relief remain largely unknown. An emerging body of evidence supports that $\mathrm{CB}_{2} \mathrm{R}$ agonist compounds may prove to be powerful novel therapeutic candidates for the treatment of chronic pain.
\end{abstract}

\section{Introduction}

Chronic pathological pain is one of the most common reasons to seek medical attention and is a worldwide epidemic [1]. Chronic pain becomes pathological as a consequence of abnormal pain signaling and is often manifested in numerous diseases, such as diabetes, arthritis, amyotrophic lateral sclerosis (ALS), multiple sclerosis (MS), and cancer [2-6]. Glial cells, which include oligodendrocytes, astrocytes, and microglia, have been found to play key roles when chronic pain becomes pathological. Given less is known about the involvement of oligodendrocytes, this paper will focus primarily on astrocytes and microglial cells in chronic pain processing.

Cannabinoid compounds are emerging as novel therapeutic targets for the treatment of chronic neuropathic pain [7]. These compounds, with subsequent $\mathrm{CB}_{1}$ and $\mathrm{CB}_{2}$ receptor $\left(\mathrm{CB}_{1} \mathrm{R}\right.$ and $\mathrm{CB}_{2} \mathrm{R}$, resp. $)$ activation, are able to modulate pain through a number of mechanisms including microglial mechanisms [8]. This paper will first discuss how normal pain becomes pathological and the role of activated glia in mediating such pain. These sections will be followed by addressing cannabinoid-mediated modulation of glial proinflammatory factors, which are known to produce chronic neuropathic pain in animal models. An emphasis will be made on the $\mathrm{CB}_{2} \mathrm{R}$. Given that this paper focuses on the action of the $\mathrm{CB}_{2} \mathrm{R}$, a discussion is included on the current states of clinical trials examining the potential efficacy of $\mathrm{CB}_{2} \mathrm{R}$ agonists as pain therapeutics.

\section{Normal versus Pathological Pain}

2.1. Acute Pain Signaling. Acute pain processing is distinct from the etiology underlying chronic pathological pain. Distinguishing the cellular responses and underlying signaling cascades that are unique to pathological pain may prove critical in understanding why many neuronally targeted treatments do not prove to be effective in relieving chronic pathological pain in the clinical setting. In acute pain, such as that caused by high intensity stimuli from mechanical stimulation (e.g., pinprick), unmyelinated $\mathrm{C}$ and lightly myelinated $\mathrm{A} \delta$ nociceptive nerve fiber terminals in the body depolarize and transduce this information into action 
potentials that travel through the peripheral axon to the dorsal root ganglia (DRG). The centrally projecting terminals of these nociceptors predominantly enter the spinal cord dorsal horn to reach the superficial (laminae I-II) and deeper lamina IV-V and synapse onto second order pain projection neurons located in lamina I, IV, and V [911]. The classical neurotransmitter primarily responsible for synaptic communication between nociceptors and pain projection neurons is the excitatory amino acid glutamate. Glutamate then binds and activates the ionotropic $\alpha$-amino3hydroxyl-5-methyl-4-isoxazolepropionic acid (AMPA) and kainate receptors as well as metabotropic glutamate receptors (mGluR 1, 3, 5, and 7) [12]. Additionally, a number of nociceptive-related neuropeptides acting in the spinal cord dorsal horn have been identified to play key roles in pain neurotransmission. For example, the classic neuropeptide, substance $\mathrm{P}$, is released from primary nociceptive afferents [13]. Substance $P$ then binds and activates its receptor, neurokinin 1 (NK1), which is present in high concentrations on dorsal horn lamina I neurons. Both substance P and its NK1 receptor are widely known to play a significant role in nociceptive processing [14]. These spinal cord nociceptive neurotransmitters, along with their receptors, are critical for activating second-order neurons, which communicate to supraspinal pain-processing centers and elicit reflexive and protective responses to avoid potential or further tissue damage.

2.2. Central Sensitization. However, under some circumstances, incoming nociceptive signaling is prolonged leading to clinical manifestations of pathological neuronal signaling. Examples of such pathological states are hyperalgesia, which is decreased threshold to nociceptive stimuli, and dynamic tactile allodynia, which is increased sensitivity to nonnociceptive light touch. Both pain states often occur in regions beyond the tissue-injured site. The underlying neurobiological events initiated by prolonged nociceptive signaling include increased synaptic function triggered within the central nervous system. Specifically, these events are known to occur within the dorsal horn of the spinal cord and culminate in a process termed spinal sensitization of pain projection neurons $[15,16]$. Once triggered, this central sensitization is sustained despite the termination of noxious input. Experimentally, continued activity is substantially extended following the end of the stimulus application [17, 18]. These seminal early studies suggested that pain may be experienced even in the absence of peripheral noxious stimuli.

Pathological pain results from inflammation and/or trauma to peripheral nerve(s), tissue(s), or the central nervous system (CNS) and may arise as a complication to numerous medical conditions. Various animal models have been developed to induce conditions similar to those observed clinically. Neuropathic pain is commonly studied in models of peripheral nerve injury/inflammation. Models of diabetic neuropathy, chemotherapy-induced pain, postsurgical pain, and osteoarthritis pain are well-established examples, and reports of these are cited throughout this paper. Although distinct in disease etiology, peripheral neuropathies share in the manifestation of pathological pain. This pathological processing is initially triggered by incoming noxious signals from nociceptors leading to central sensitization. One classically known mechanism for spinal sensitization involves excitation of pain projection neurons in the superficial laminae of the spinal cord dorsal horn as well as wide dynamic range neurons (WDR) located in deeper lamina IV and V that process the rapid and intense nerve depolarizations. Following prolonged and significant depolarization by the actions of glutamate and substance $\mathrm{P}$, spinal pain projection neurons become sensitized, leading to the activation of N-Methyl-D-Aspartic Acid (NMDA) receptors that are normally inactive due to a $\mathrm{Mg}^{2+}$ plug within the cation channel. Prolonged depolarization induces $\mathrm{Mg}^{2+}$ release followed by enhanced influx of $\mathrm{Ca}^{2+}[19,20]$. A cascade of intracellular events occurs, which ultimately leads to postsynaptic enhancement of AMPA and mGlu receptor action, thereby increasing synaptic efficacy [21].

2.3. Sensory Changes in Pathological Pain. Increasing synaptic efficacy exerts profound changes in dorsal horn sensory processing $[16,22]$. Indeed, enhanced synaptic efficacy, initiated by low intensity mechanosensitive $\mathrm{A} \beta$ fibers, occurs at synapses on pain projection neurons in the dorsal horn [23], creating the perceptual equivalent of a noxious stimulus. Activated low-intensity $\mathrm{A} \beta$ fibers, that carry nonpainful information such as light touch, are now capable of activating high intensity nociceptive neurons resulting in the clinical phenomenon known as allodynia. That is, nonpainful light touch is coded as painful, leading to a pain sensation that occurs in the absence of noxious input. Despite the fact that the stimulus is initiated in the periphery, its manifestation is a consequence of central changes like sensitization in the spinal cord [15]. Both allodynia and hyperalgesia are a hallmark of pathological pain $[15,16]$.

\section{The Role of Glia in Pathological Pain}

3.1. Glial Activation. While it is clear that neuronal processes are critical for spinal sensitization leading to pathological pain signaling, nonneuronal glial mechanisms are also important [24]. Under persistent pathological conditions, the availability of neuropeptides, such as substance $\mathrm{P}$ and amino acid neurotransmitters like glutamate is increased and able to bind their receptors not only on neurons, but also on astrocytes as well as parenchymal and perivascular microglia. Glial "activation" ensues and sets in motion a cascade of excitatory signaling events [25].

At the onset and during pathological pain conditions, multiple signaling cascades within glia are triggered including the activation of $\mathrm{p} 38$ mitogen-activated protein kinase (p-p38MAPK) and the c-Jun N-terminal kinase (JNK) pathways via phosphorylation events. Consequently, downstream cascades are initiated, including NF- $\kappa \beta$ activation, a cytokine nuclear transcription factor, and lead to the subsequent production of proinflammatory cytokines such 
as interleukin- $1 \beta$ (IL- $1 \beta$ ) and tumor necrosis factor- $\alpha$ (TNF$\alpha$ ), as well as chemokines (chemoattractant cytokines) [2530]. It is important to note that multiple signaling pathways can activate NF- $\kappa \beta$ leading to altered gene expression. For example, glially released TNF- $\alpha$, when bound to its receptor, leads to phosphorylation of p38MAPK (p-p38MAPK) and NF- $\kappa \beta$ activation. Alternatively, IL- $1 \beta$, when bound to its receptor, can directly activate NF- $\kappa \beta[31,32]$. In the spinal cord, IL- $1 \beta$ and TNF- $\alpha$ can further directly excite neurons because neurons express receptors for these cytokines. Indirect neuronal stimulation occurs by cytokineinduced release of additional excitatory mediators such as prostaglandins and nitric oxide (NO). It has been reported that spinal p38MAPK, JNK, and the extracellular signalregulated kinase, ERK1/2, also referred to as MAPK3/1, are critical mediators of pathological pain in animal models [33-37]. For example, sciatic nerve ligation (SNL), a wellcharacterized rodent model of peripheral nerve injury, leads to increased p38MAPK in spinal astrocytes and microglia, and upon spinal pharmacological blockade with the pp38MAPK inhibitor SB203580, p38MAPK activation with associated neuropathic pain is diminished [34]. Although very little is known about oligodendrocyte signaling in chronic pain, emerging evidence suggests that these cells are not merely passive observers to chronic pain, but rather these cells may also upregulate (phosphorylated) p-AKT, a factor that has been found to mediate apoptosis, cell migration, and motility in the dorsal horn of the spinal cord. Phosphorylated-AKT may be critical to the previously discussed spinal cord neuronal sensitization process [38].

It is notable that activated microglia respond to and produce inducible nitric oxide synthase (iNOS), and likewise activated astrocytes release NO $[39,40]$. The production of NO by both neurons and glia is characteristic of neuroinflammation [41-44]. Thus, upon spinal glial activation from NO (among several other activating factors), intracellular signaling cascades lead to increases in cytokines and diffusible factors that further activate neighboring neurons and glia. That is, IL- $1 \beta$ and TNF- $\alpha$ lead to a feed-forward loop of further JNK and MAPK signaling, NF- $\kappa \beta$ activation, and increased NO, cytokine, and chemokine production, which all contribute to ongoing pathological pain.

While microglia and immune-like astrocytes respond to spinal IL- $1 \beta$ and TNF- $\alpha$ resulting in pathological pain, increased peripheral immune cell (neutrophils, lymphocytes, monocytes, macrophages) migration to critical regions of nociceptive processing, such as the DRG and the spinal cord dorsal horn also occurs in response to cytokines [39, 45-47]. The specific underlying mechanisms are poorly understood. What is known, however, is that cellular enrichment at these critically important anatomical sites takes place via increased immune cell actin remodeling and proliferation in response to chemotactic signaling $[46,48,49]$.

3.2. Glial Morphology and Activation Markers. Activated glial cells typically undergo changes in morphology, proliferation, and migration, termed gliosis. For example, astrocytes upregulate vimentin and glial fibrillary acidic protein (GFAP) and become highly arborized with thickened processes [50]. These changes in morphology and increased GFAP expression are often considered a sign of spinal cord pathogenesis during the expression of neuropathic pain in animal models and are thought to be indicative of CNS inflammatory processes $[26,50,51]$. A report examining cellular enrichment of the spinal cord in a peripheral nerve injury ratmodel of pain identified that microglial cells are more proliferative and undergo more clustering than astrocytes [52]. Microglia, when activated, typically upregulate the cellular makers, ionized calcium binding adaptor molecule-1 (Iba-1), and CD11b/c, also known as OX42 [52-57]. However, the upregulation of these proteins is not always indicative of proinflammatory phenotypic processes of glial cells. For example, activated microglia can additionally express ED2, a classic anti-inflammatory marker, suggesting that activated microglia are not solely engaged in proinflammatory processes $[58,59]$.

Although these cellular changes have been widely documented in animal models of chronic pain, less is known about whether glial activation always reflects inflammation and whether it contributes to chronic pain in humans. What is known is that gliosis occurs within the spinal cord of patients with neuroimmune diseases such as ALS, MS, and spodylotic myopathy $[60,61]$. It is noteworthy that these patients often report chronic pain symptoms $[4,6]$. Furthermore, postmortem tissue analysis from these patients often reveals gliosis concomitant with the disease, and as such, these glial changes may contribute to chronic pain in these patients. However, the role of these cellular markers in animal models of chronic pain are not fully understood, as reports show a disconnection between glial marker upregulation, proinflammatory signaling markers, and behavior associated with pain. For example, while fluorocitrate attenuated upregulation of GFAP in mice with the chronic constriction injury of the sciatic nerve (CCI), another commonly used model of chronic neuropathic pain, chronic pain symptoms remained unchanged [55]. Additionally, in separate studies utilizing a paw incision model of postsurgical pain, chronic morphine administered subcutaneously delayed the normal resolution of allodynia and hyperalgesia, which was observed with saline-injected controls. Tissues from the corresponding groups in this study were analyzed for GFAP, Iba-1, p-ERK, and p-p38MAPK, with saline-injected animals showing clear behavioral resolution, which was absent in the morphine-treated groups. Strikingly, no differences in GFAP or Iba-1 immunoreactivity were observed between saline-or chronic morphine-treated groups. However, p-ERK and p-38MAPK were increased in the chronic morphine-treated groups, corresponding to their behavioral profile [62]. Conversely, perivascular microglia have been shown to remain in an activated state as assessed by immunohistochemical detection of ED2 during the presence of pain reversal [63]. From these studies, and as noted previously, the presence or absence of glial activation, per se, is too simplistic to fully understand a glial role in chronic pain. It is possible that microglia can remain activated while producing and releasing anti-inflammatory factors that ultimately lead to pain suppression $[64,65]$. 
3.3. Downstream Glial Signaling of Cytokines. Both IL- $1 \beta$ and TNF- $\alpha$ induce chemotactic activity on CNS microglia and astrocytes. Indeed, once activated, microglia and astrocytes are well known to undergo migration and proliferation in the spinal cord under conditions of chronic pain [52]. Recently, it has been shown that an increase in glial cell numbers occurs within the ipsilateral dorsal horn of the spinal cord following unilateral peripheral nerve injury [66].

During pathological pain states, peripheral immune cells additionally migrate to critical CNS pain processing sites. However, the contribution of peripheral versus CNS immune cell actions with subsequent cytokine signaling to neuropathic pain is not fully understood. Rat spinal cord meninges contain peripheral immunocompetent cells such as macrophages, and following in vitro stimulation of isolated meninges with the administration of the HIV-1 envelope glycoprotein gp120, IL- $1 \beta$, and TNF- $\alpha$ were released [67]. These data suggest that meningeal cells, characterized to include peripheral immune cells like macrophages, contribute to ongoing spinal cord glial activation via proinflammatory cytokine actions. Given these compelling data, we explored the possibility that anatomically intact meninges contain macrophages that express IL-1 $\beta$. Here, we utilized immunofluorescent histochemical procedures followed by detection with confocal microscopy and demonstrated that IL- $1 \beta$ is indeed present within the meningeal layers surrounding the spinal cord of neuropathic rats (Figures 1(a), 1(b), and 1(c)). Histologically, these data confirm prior reports showing, via in situ hybridization, that IL-1 $\beta$ mRNA was colabeled with Iba-1 [68], indicating infiltrating monocytes/macrophages. Within deeper dorsal horn laminae, IL- $1 \beta$ is colabeled with Iba- 1 that identifies microglia (Figures 1(d), 1(e), and 1(f)). While we found some colabeling of IL- $1 \beta$ with GFAP, no co-labeling with NF$\mathrm{H}$ (data not shown) within the dorsal horn of the spinal cord was observed. Given the evidence that immune cell and glialderived IL-1 $\beta$ (as well as other cytokines discussed, above) has a critical role in animal models of pathological pain, targeting neurons alone is now thought to be an incomplete approach. Immune and glial cells within the CNS may serve as novel targets to modulate enduring pathological pain.

3.4. Glia in DRG. Glial satellite cells in the DRG are also important in mediating pathological pain in addition to spinal cord glial cytokine actions. Satellite glia completely surround DRG neurons and together form a functional unit [69]. Glial satellite cells become activated and contribute to pathological pain in response to peripheral injury by several possible mechanisms [69-73]. For example, glial satellite cells generate cytokines, including IL- $1 \beta$ and TNF- $\alpha$, which have been characterized to activate peripheral immune cells $[71,73-75]$. DRG invasion by peripheral immune cells [76-79] occurs as a consequence of peripheral nerve injury $[29,80,81]$. Neuroimmune activity is a potential mechanism because DRG neurons have receptors for these cytokines and, when stimulated, lead to the production of the chemokine monocyte chemoattractant protein-1 (MCP1 ), which induces peripheral immune cell migration to the
DRG $[49,81]$. In addition, neuroactive IL- $1 \beta$ and other immune signals released from satellite glia act in a paracrine fashion to stimulate neighboring sensory ganglia and their axons, creating allodynia $[69,73,82-84]$. Indeed, stimulating sensory neurons in the DRG with IL- $1 \beta$ leads to further axonal release of substance $\mathrm{P}$ [85] within the dorsal horn of the spinal cord. IL- $1 \beta$ acts in a p-p38MAPK-dependent manner in the DRG [82], and increased p-p38MAPK expression is well characterized in the DRG following peripheral nerve injury that produces pathological pain $[82,86,87]$. Here we show an example of DRG IL- $1 \beta$ in close proximity with sensory neurons. IL- $1 \beta$ is colabeled with GFAP-positive satellite cells within a DRG from an animal with ongoing CCI-induced neuropathy which is shown (Figures $1(\mathrm{~g}), 1(\mathrm{~h})$, and 1(i)). The actions of glially released cytokines such as IL$1 \beta$ on nearby neuronal processing in both spinal cord and DRG indicate that not only neuronal, but also glial systems are altered during conditions that lead to and promote chronic pain. These data strongly suggests that in order to efficiently control chronic or pathological pain associated with numerous disease states, including diabetic neuropathy and cancer, promising therapeutics will need to address this underlying glial contribution.

3.5. Modulating Glial Activation for Pain Relief. Several compounds specifically targeting glial activation have been developed with the potential for the treatment of pain. While a full discussion of such compounds is beyond the scope of this paper (for review, see [88]), one example drug is discussed here to underscore the supposition that altering glial activation states is a highly promising approach to control pathological pain. An example of a compound that targets microglial activation is minocycline, a wellcharacterized microglial inhibitor [89]. In numerous animal models, minocycline robustly produces antiallodynia and hyperalgesia [55, 89-91]. However, globally disrupting the function of microglia as well as peripheral immune cells may produce unintended side effects, such as increased susceptibility to CNS infection [92]. An alternative approach using cannabinoid-related compounds appears to be very promising for clinical pain relief. Cannabinoids may act in an anti-inflammatory manner, and these anti-inflammatory actions may have a glial role [7, 93]. Intriguingly, the cannabinoid receptor subtype $2, \mathrm{CB}_{2} \mathrm{R}$, has been identified primarily on microglia [94]. Published reports strongly suggest that activation of this receptor subtype leads to pain control $[95,96]$. In the remainder of this paper we will provide a brief overview of cannabinoids, specifically discussing published data in support of cannabinoid-related compounds for pain control with a glial-centric view.

\section{The Endocannabinoid System}

4.1. Components of the Endocannabinoid System. The endogenous cannabinoid (endocannabinoid) system is comprised of multiple components, including receptors, ligands, and degradative enzymes. Each will be discussed in turn, below. Within the past 6 years, an explosion of reports has 
Iba-1

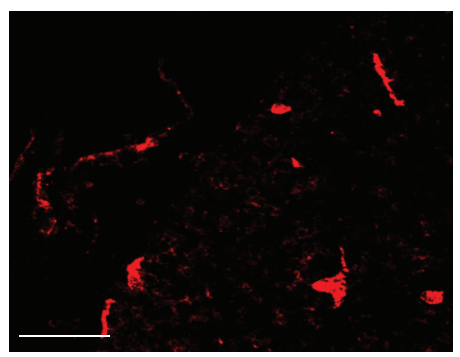

(a)

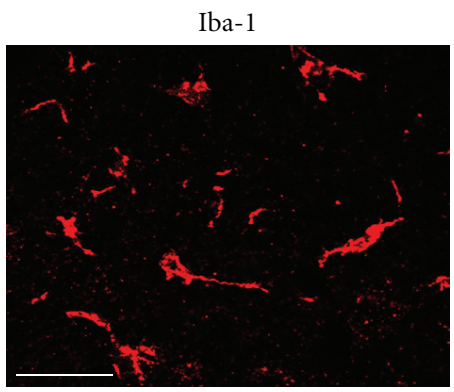

(d)

GFAP/NF-H

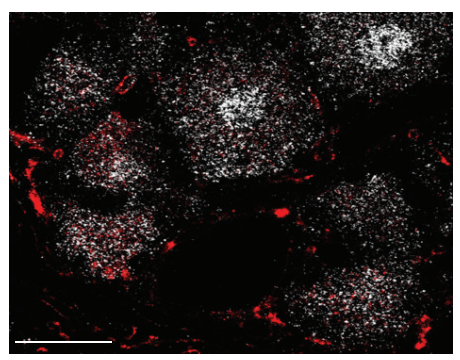

(g)

Iba-1

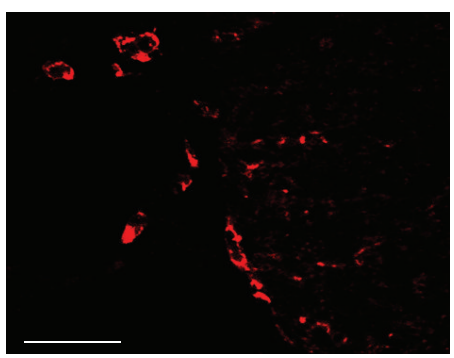

(j)
IL- $1 \beta$

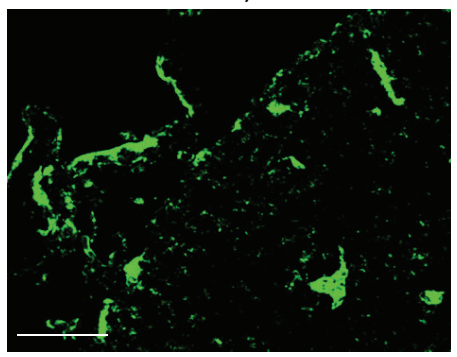

(b)

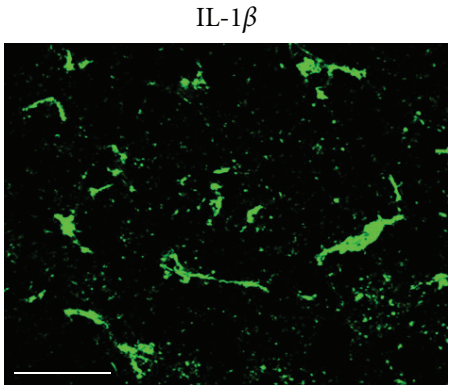

(e)

\section{IL- $1 \beta$}

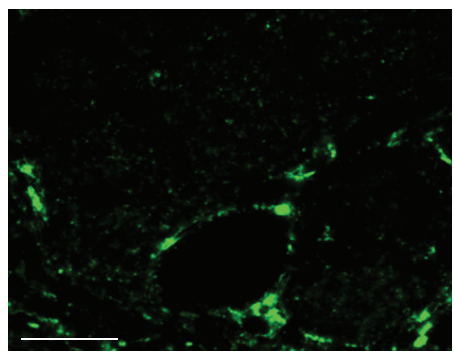

(h)

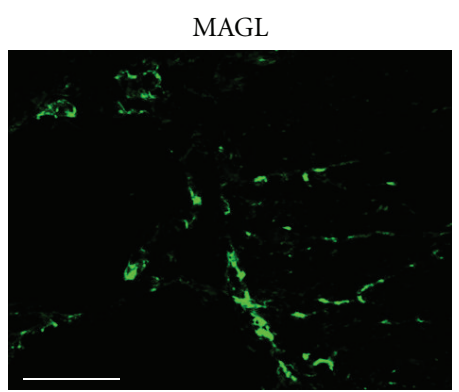

(k)

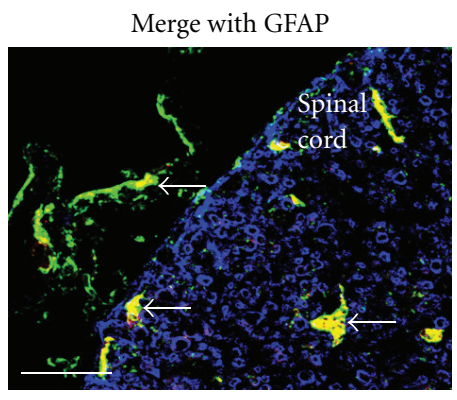

(c)

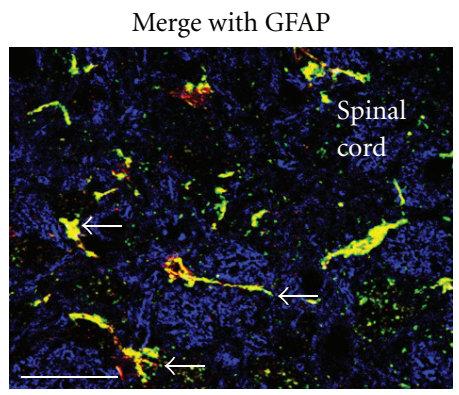

(f)

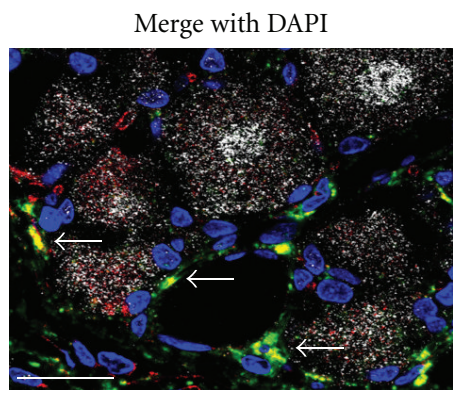

(i)

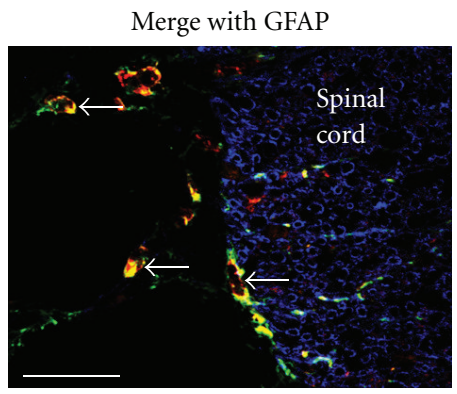

(1)

FIGURE 1: Qualitative confocal images of cellular immunostaining. (a) Immunostaining of Iba-1 (red) for infiltrating macrophages and microglia in the meninges and superficial white matter of the spinal cord in a rat with ongoing neuropathy. (b) Immunostaining with IL- $1 \beta$ (green). (c) Arrows indicate yellow colabeling of IL-1 $\beta$ - and Iba-1-positive cells and not with GFAP (blue). (d) Immunostaining of Iba-1 (red) in the deeper laminae of the spinal cord dorsal horn in a rat with ongoing neuropathy. (e) Immunostaining with IL- $1 \beta$ (green). (f) Arrows indicate yellow colabeling of IL- $1 \beta$ - and Iba-1-positive cells and not with GFAP (blue). (g) DRG immunostaining of GFAP positive satellite cells (red) and neurons stained for neurofilament-heavy (NF-H, white) from a rat with ongoing neuropathy. (h) DRG immunostaining for IL-1 $\beta$ (green). (i) Arrows indicate yellow DRG IL-1 $\beta$ and GFAP colabeling with DAPI nuclear labeling (blue). (j) Immunostaining of Iba-1 (red) in meninges and superficial laminae of the dorsal horn spinal cord in a rat with ongoing neuropathy. (k) Immunostaining of MAGL (green). (l) Arrows indicate yellow colabeling of MAGL and Iba-1-positive cells, and not with GFAP (blue). Scale bars for all images indicate $20 \mu \mathrm{m}$. 
occurred on the endocannabinoid system and its potential role in modulating numerous disease processes, including those associated with pathological pain conditions. This is due, in part, following the identification of cells that express cannabinoid receptors and subsequent signaling mechanisms. In general, endocannabinoid signaling was thought to involve only neurons [97-99]. Glia in the CNS had no role. However, immune cells, including microglia are now known to be involved in endocannabinoid signaling cascades (discussed further, below). While the underlying mechanisms involved in mediating the therapeutic effects of the endocannabinoid system are still a mystery, new breakthroughs have elucidated the bioavailability of endocannabinoids and cannabinoid receptor action with regard to the mediation of pain processing.

The two widely acknowledged cannabinoid receptors are the $C_{1} R$ and the $C B_{2} R$. Both have shown great potential for the development of therapeutics targeted at pain control. The putative cannabinoid receptor subtype of the "orphan" receptor, GPR55 [100], remains controversial as several reports indicate opposite pharmacological profiles [101-104]. Research targeting this receptor with cannabinoid ligands has just begun to gain momentum [105-107]. However, there are reports that at least five distinct cannabinoid receptors have been identified [8]. The most well-characterized cannabinoid receptor, the $C_{1} R$, is primarily found on neurons within the heart, small intestine, urinary bladder and vas deferens in the periphery and, within the CNS, has the highest concentrations in the cerebellum, hippocampus, basal ganglia and cerebral cortex [108-110]. However, the $\mathrm{CB}_{2} \mathrm{R}$ has a distinctly different distribution and is primarily found on immune cells [111-113]. Current evidence demonstrates that the endocannabinoid system may have potential as a target for pain control, and thus the remainder of this paper will focus on the endocannabinoid system relative to pain therapeutics.

\subsection{Classical Cannabinoid Receptor Signaling. Both the $\mathrm{CB}_{1} \mathrm{R}$} and $\mathrm{CB}_{2} \mathrm{R}$ belong to the $\mathrm{G}$-protein coupled receptor (GPCR) superfamily and couple to the inhibitory $G_{i / o}$ and $G_{i}$, respectively. Activation of either receptor leads to p42/44 MAPK signaling and inhibits adenylate cyclase, limiting the ATP production of cyclic AMP (cAMP) and leading to lessened activity of protein kinase $\mathrm{A}$ (PKA) $[108,114,115] . \mathrm{CB}_{1} \mathrm{R}$ activation, but not $\mathrm{CB}_{2} \mathrm{R}$ activation, can modulate ionic $\mathrm{Ca}^{2+}$ and $\mathrm{K}^{+}$channels, which is blocked with pertussis toxin, indicating that the $\mathrm{CB}_{1} \mathrm{R} \mathrm{G}_{\mathrm{i} / \mathrm{o}}$ proteins are directly responsible for modulation of these ion channels [108, 116-118]. Evidence exists that $\mathrm{CB}_{1} \mathrm{R}$ activation can activate p38MAPK in vitro $[119,120]$. However, this is a paradoxical finding, because activation of p38MAPK can lead to increased pain signaling, which opposes the therapeutic efficacy of $\mathrm{CB}_{1} \mathrm{R}$ agonists for pain control. A mechanism for these findings has not been elucidated, but may include or be wholly dependent on noncannabinoid receptor signaling cascades. No similar in vivo report exists detailing p38MAPK activation from $\mathrm{CB}_{1} \mathrm{R}$ activation.
Although a few of the above mentioned signaling properties of the $\mathrm{CB}_{1} \mathrm{R}$ have proven to be sufficient in leading to pain control, the practical implications of $\mathrm{CB}_{1} \mathrm{R}$ agonists in a clinical setting are limited. The $\mathrm{CB}_{1} \mathrm{R}$ was first discovered as the receptor for the major psychoactive ingredient in Cannabis sativa, $\Delta^{9}$-tetrahydrocannabinol (THC) which was first isolated in 1965 [121-123]. The attractiveness for clinical application of compounds selectively acting on the $\mathrm{CB}_{1} \mathrm{R}$ is limited by the development of tolerance [124] and its psychotropic effects [7, 125], which include cognitive impairment [126], catalepsy [127-129], hypothermia [127129], and negative impacts on learning and memory [130, 131]. This is in contrast to the effects of cannabidiol, another active compound of marijuana [132]. Cannabidiol does not produce unwanted CNS side effects by itself, but it is not widely thought to act robustly at either the $\mathrm{CB}_{1} \mathrm{R}$ or the $\mathrm{CB}_{2} \mathrm{R}$ due to low binding affinities observed in vitro [132]. Despite low $\mathrm{CB}_{1} \mathrm{R}$ and $\mathrm{CB}_{2} \mathrm{R}$ binding properties that cannabidiol possesses, it remains as a promising therapeutic for chronic pain treatment based on its anti-inflammatory actions.

In vivo, cannabidiol within the CNS may still produce $\mathrm{CB}_{2} \mathrm{R}$ activation resulting in anti-inflammatory properties. It was recently demonstrated in a mouse model of diabetic neuropathy that intranasal administration of cannabidiol produces anti-inflammatory actions via downregulation of p-p38MAPK in spinal glia [133]. In this animal model, spinal glia are characterized to become activated and contribute to neuropathic conditions resulting in mechanical sensitivity and thermal hyperalgesia through the activation of proinflammatory signaling cascades like p38MAPK [134136]. Cannabidiol is sufficient to produce neuropathic pain relief that is dependent on $\mathrm{CB}_{2} \mathrm{R}$ activation [133]. These data demonstrate that there is a critical link between cannabidiol's therapeutic action, which includes a $\mathrm{CB}_{2} \mathrm{R}$ role, to spinal glial activation and pain control.

4.3. Cannabinoid 2 Receptors. The $\mathrm{CB}_{2} \mathrm{R}$ is predominantly found on immune cells, such as lymphocytes, neutrophils, and macrophages, with the highest peripheral concentrations in the spleen, lymph nodes, and testes [94, 111-113]. Within the CNS, the $\mathrm{CB}_{2} \mathrm{R}$ is found primarily on microglia, and some neurons specifically within the hippocampus, cortex, and substantia nigra $[110,137,138]$. However, the spinal cord and DRG distribution of the $\mathrm{CB}_{2} \mathrm{R}$ is an area of much debate, as the current literature frequently reports conflicting data. One report suggests that the $\mathrm{CB}_{2} \mathrm{R}$ is expressed only on neurons [139], while a separate report reveals $\mathrm{CB}_{2} \mathrm{R}$ expression on microglia, and to a lesser extent on neurons [96], and yet another report demonstrates $\mathrm{CB}_{2} \mathrm{R}$ on microglia with no neuronal expression [138]. The discrepancy between studies identifying the $\mathrm{CB}_{2} \mathrm{R}$ expression on specific cell types may be partially due to the recent discovery of two separate isoforms of the $\mathrm{CB}_{2} \mathrm{R}$. The most prevalent isoform of the $\mathrm{CB}_{2} \mathrm{R}$ within the periphery, termed "CB2B", is found extensively within the spleen, and to a lesser degree, in the liver, intestines, and leukocytes. The shorter isoform, "CB2A", is predominately found within the brain, testes, and to a lesser degree in the spleen, kidney, muscle, and leukocytes [140]. 
As most commercially available antibodies for the $\mathrm{CB}_{2} \mathrm{R}$ utilize $\mathrm{CB}_{2} \mathrm{R}$ isolated from spleen, it is possible that the $\mathrm{CB} 2 \mathrm{~B}$ isoform, found in much greater abundance within the spleen than the CB2A isoform, is the isoform recognized by most commercially available antibodies for immunohistochemistry. For example, Wotherspoon and colleagues, utilizing immunohistochemistry and $\mathrm{CB}_{2} \mathrm{R}$ null mice, showed that $\mathrm{CB}_{2} \mathrm{R}$ expression was induced by nerve ligation and was localized to the spinal cord superficial lamina ipsilateral to the nerve damage, while null $\mathrm{CB}_{2} \mathrm{R}$ mice revealed no upregulation [139]. The authors suggest that $\mathrm{CB}_{2} \mathrm{R}$ was expressed on sensory afferent terminals because colocalization with growth-associated protein- 43 and the neuropeptide galanin, was observed. However, Romero-Sandoval and colleagues demonstrated, also through immunohistochemistry, that the $\mathrm{CB}_{2} \mathrm{R}$ was primarily found on parenchymal and perivascular microglial cells. The authors additionally noted very limited and sparse staining in neurons $[63,96]$. Lastly, in a study using in situ hybridization (ISH), $\mathrm{CB}_{2} \mathrm{R}$ mRNA was present on immunohistochemically identified microglia [138].

Based on the above-noted discrepancies of the cellular localization of the $\mathrm{CB}_{2} \mathrm{R}$ in the spinal cord, one possible consideration should be the animal model that is utilized. It has been demonstrated that the $\mathrm{CB}_{2} \mathrm{R}$ may not be upregulated in the dorsal horn of the spinal cord in inflammatory pain models, but rather in chronic neuropathic pain models [138]. This suggests that the degree of $\mathrm{CB}_{2} \mathrm{R}$ upregulation in chronic pain is heavily dependent on the model. The type of the injury induced in a specific model may dictate the overall receptor upregulation and the cellular colocalization of the $\mathrm{CB}_{2} \mathrm{R}$. The $\mathrm{CB}_{2} \mathrm{R}$ isoform distribution within the spinal cord and DRG under basal and chronic inflammatory pain conditions has not been systematically examined. Given these potential confounds, identifying the cellular distribution of the $\mathrm{CB}_{2} \mathrm{R}$ within the spinal cord remains elusive.

4.4. Bioavailability of Endocannabinoids. The endogenous cannabinoid system is also comprised of a number of endogenous ligands for the $\mathrm{CB}_{1} \mathrm{R}$ and $\mathrm{CB}_{2} \mathrm{R}$, which includes anandamide (AEA), 2-arachadonyl glycerol (2-AG), as well as degradative enzymes [141, 142]. The endocannabinoids AEA and 2-AG are produced and released from neurons and microglia [94], which are controlled by enzymatic hydrolysis of fatty acid amide hydrolase (FAAH) and monoacylglycerol lipase (MAGL), respectively $[141,143]$. The enzyme MAGL has been identified on presynaptic axon terminals in brain, suggesting that it can terminate 2 -AG activity in presynaptic nerve terminals $[142,144]$ of centrally projecting afferent nociceptors in the spinal cord dorsal horn. Interestingly, it has been found that microglia release 2-AG, and functional MAGL has been described in primary microglial cell cultures [145]. Recently, a novel isoform of MAGL has been described in BV-2 microglial cell cultures, although it is uncertain if this isoform occurs within microglial cells in vivo [146]. To date, MAGL cellular coexpression utilizing immunohistological techniques has not been performed on pain-relevant spinal cord dorsal horn regions or spinal cord tissue. We show here, utilizing confocal microscopy, that within the meningeal layer surrounding the spinal cord taken from behaviorally verified neuropathic rats, MAGL is colabeled with Iba-1-positive infiltrating monocytes. In superficial laminae, MAGL is colabeled with either resident microglia or infiltrating monocytes/macrophages (Figures $1(\mathrm{j}), 1(\mathrm{k})$, and $1(\mathrm{l})$ ). We additionally observed in the deeper dorsal horn laminae, that MAGL is colabeled with Iba-1-positive microglia and morphologically identifiable neuronal cell bodies (data not shown).

4.5. The Implications of the Endocannabinoid System in Pain Modulation. Following peripheral nerve or tissue injury, increased expression of endocannabinoids, $\mathrm{CB}_{2} \mathrm{R}, \mathrm{FAAH}$, and MAGL occurs in DRG and spinal cord [94, 109, 147]. For example, AEA and 2-AG are upregulated in DRG following L5 spinal nerve ligation (SNL), a well-described animal model that leads to neuropathic pain [109]. Additionally, in a paw incision model of pain, 2-AG, widely characterized to produce analgesia, was found to be upregulated in the ipsilateral lumbar spinal cord on days 3 and 9 and in the contralateral lumbar spinal cord on days 1 and 9 after surgery [63]. These data suggest that endocannabinoid compounds may act to counterbalance the cytokine actions known to mediate neuropathic pain.

Recent studies show that exogenous application of the endocannabinoids, AEA and 2-AG, leads to pain control. Exogenous AEA administered spinally reverses carageenaninduced nociception [148], and exogenous 2-AG injected into the hindpaw blocks nociceptive responses due to formalin injection $[149,150]$. Paradoxically, administration of exogenous AEA to the hindpaw or high intrathecal doses produce nociceptive behavior and, in both cases, is mediated by the ionotropic transient receptor potential cation channel, superfamily V subtype 1 (TRPV-1) $[148,151]$. Several reports detail that the actions of AEA may be mediated by TRPV-1, and as such, caution must be taken when assigning endocannabinoid actions to only the $\mathrm{CB}_{1} \mathrm{R}$ or the $\mathrm{CB}_{2} \mathrm{R}$.

Manipulating the enzymes responsible for the bioavailability of AEA or 2-AG is additionally effective for pain control. Altering endocannabinoid levels by inhibiting the actions of MAGL and/or FAAH increases available endogenous AEA and 2-AG and results in therapeutic actions. Following localized administration of MAGL inhibitors (JZL184, URB602), into rat hindpaws increases local levels of 2-AG, with simultaneous attenuation of formalin-induced pain in rats $[149,150]$. Additionally, systemic administration of FAAH inhibitors (PF-3845, URB597), MAGL inhibitors (JZL184, URB602) or the dual FAAH/MAGL inhibitor, JZL195, increases CNS levels of AEA and 2-AG, with attenuation of CCI-induced pain in mice $[152,153]$. Specifically, the pharmacological FAAH inhibitor, PF-3845, decreased allodynia and hyperalgesia in CCI-induced neuropathic mice without the development of tolerance [129]. Numerous studies have demonstrated that MAGL inhibitors increase 2-AG accumulation $[129,152,154]$. However, recent studies indicate that following challenge with $\mathrm{CB}_{1} \mathrm{R}$ agonists, increased 2-AG availability leads to $\mathrm{CB}_{1} \mathrm{R}$ downregulation, 
desensitization, and lessened $\mathrm{CB}_{1} \mathrm{R}$ effects [127, 129]. These data suggest that significantly increasing the levels of 2-AG may not be a clinically viable approach for treating chronic pain conditions.

Although pain behavior is suppressed following exogenous administration of 2-AG and AEA or by increased levels of endocannabinoids via enzyme inhibitors, the exact mechanisms of these cannabinoids underlying the modulation of inflammation and pain are not well understood. Studies are currently underway by several groups to elucidate the mechanisms whereby the endocannabinoid system is able to lead to pain control $[63,129,152,153]$. Alkaitis and colleagues, utilizing dual $\mathrm{CB}_{1} \mathrm{R}$ and $\mathrm{CB}_{2} \mathrm{R}$ antagonists, AM281 and AM630, respectively, recently found that the endocannabinoid system plays critical roles in the resolution of allodynia from surgical hindpaw incision, an animal model of postsurgical pain [63]. In addition, blocking the activation of both the $C_{1} R$ and the $C_{1} R$ resulted in increased p-p38MAPK levels in this model of postsurgical pain, suggesting that constitutive endocannabinoid actions play a role in modulating $\mathrm{p}$-p38MAPK. These findings support that the endocannabinoid system alters factors which are critical mediators of inflammatory processes underlying pain responses in a wide range of medical conditions where chronic pain is a component. Although speculative, $\mathrm{CB}_{2} \mathrm{R}$ actions during chronic pain may be primed for enhanced activity to ultimately produce pain modulation following $\mathrm{CB}_{2} \mathrm{R}$ stimulation, as downregulation and desensitization previously noted to occur with the $\mathrm{CB}_{1} \mathrm{R}$ have not been observed with the $\mathrm{CB}_{2} \mathrm{R}[7,95,155]$. Numerous synthetic $\mathrm{CB}_{2} \mathrm{R}$ agonists are currently being explored as potential therapeutic interventions for the treatment of chronic pain.

\section{Well-Characterized $\mathrm{CB}_{2} \mathrm{R}$ Synthetic Compounds}

Growing evidence that $\mathrm{CB}_{2} \mathrm{R}$ agonism appears to lack the adverse $\mathrm{CNS}$ effects that activated $\mathrm{CB}_{1} \mathrm{R}$ exerts has fueled the development of clinically viable $\mathrm{CB}_{2} \mathrm{R}$ agonists. Therefore, a strong research effort in pursuit of the development and characterization of synthetic $\mathrm{CB}_{2} \mathrm{R}$ agonists with modified chemical structures to facilitate selective binding to the $\mathrm{CB}_{2} \mathrm{R}$ over the $C_{1} R$ is ongoing. The remainder of this paper will address the current evidence of synthetic $\mathrm{CB}_{2} \mathrm{R}$ selective compounds for the treatment of different animal models of pathological pain. This is not an exhaustive review of all studies, but rather an overview. Additional reviews detailing the chemistry, bioavailability, efficacy, and kinetics of specific drug compounds are available elsewhere $[7,156,157]$.

Synthetic agonists selective for $\mathrm{CB}_{2} \mathrm{R}$ have been shown to produce anti-inflammatory effects with modulation of signaling cascades favorable for controlling chronic pain. Caution must be used in assuming that specific antiinflammatory effects seen with a particular $\mathrm{CB}_{2} \mathrm{R}$ agonist will additionally be seen with all other $\mathrm{CB}_{2} \mathrm{R}$ agonists, as the binding site for different compounds may not be the same. This factor may further influence the cellular signaling pathways that occur, downstream of cannabinoid receptor binding, and the compound's ultimate intracellular fate, such as degradation by MAGL as opposed to FAAH. Therefore, each selected $\mathrm{CB}_{2} \mathrm{R}$ agonist and its observed actions are presented in a table (Table 1). The most recent findings for each compound are summarized. JWH-015 is a $\mathrm{CB}_{2} \mathrm{R}$ selective agonist from the aminoalkylindole classification of $\mathrm{CB}_{2} \mathrm{R}$ agonists with a 27-fold affinity for the $\mathrm{CB}_{2} \mathrm{R}$ over the $\mathrm{CB}_{1} \mathrm{R}$ [158, 159]. Collectively, the aminoalkylindoles represent the most studied group of synthetic $\mathrm{CB}_{2} \mathrm{R}$ agonists. Romero-Sandoval and colleagues have recently used a wellcharacterized in vitro model of inflammation to examine the anti-inflammatory actions of JWH-015. Lipopolysaccharide (LPS), an outer cell-wall particle of Gram-negative bacteria which strongly activates innate immune cells, was given to macrophages in cell culture. It was demonstrated that incubation with JWH-015 leads to a decrease in phosphorylated extracellular signal-regulated kinase-1 (P-ERK) that is mediated by mitogen-activated kinase phosphatase (MKP) 1 and 3 [93]. MKP-3 is a selective negative modulator of the ERK-2 signaling pathway through negative feedback loop mechanisms, while in the same in vitro studies, neither JNK nor p38MAPK signaling was affected [160]. $\mathrm{CB}_{2} \mathrm{R}$ agonist treatment failed to suppress LPS-stimulated increases in $\mathrm{p}$ ERK-2 in the presence of MKP-3 inhibitors, supporting the possibility that $\mathrm{CB}_{2} \mathrm{R}$ agonists exert antiinflammatory actions via MKP-3 signaling [93]. These data support that $\mathrm{CB}_{2} \mathrm{R}$ activation, by binding highly selective synthetic agonists, may control proinflammatory processes.

Other $\mathrm{CB}_{2} \mathrm{R}$ agonists that produce therapeutic effects to control chronic pain are described below. The compound $A M 1241$, a $\mathrm{CB}_{2} \mathrm{R}$ selective agonist also from the aminoalkylindole class, has a 36-fold affinity for the $\mathrm{CB}_{2} \mathrm{R}>$ $\mathrm{CB}_{1} \mathrm{R}$ [157, 161, 162]. Despite the fact that it has been described as a protean agonist because it exerts different inverse agonist properties [162], it is widely characterized as an effective compound for pain suppression. For example, AM1241 has been found to be effective in treating experimental models of bone cancer pain. Acute and sustained intraperitoneal (i.p.) administration of AM1241 to mice decreased pain symptoms and additionally lessened the amount of bone loss during bone cancer-induced neuropathic pain. The authors suggest that these observations were mediated via the $\mathrm{CB}_{2} \mathrm{R}$, as acute behavioral effects observed were not present with the addition of SR144528, a $\mathrm{CB}_{2} \mathrm{R}$ antagonist [163]. In a separate study using two models of bone cancer pain, systemic administration of AM1241 was efficacious in reducing pain symptoms and was reliant on spinal $\mathrm{CB}_{2} \mathrm{R}$. Interestingly, the authors concluded that the actions of opioid receptors were necessary to achieve these analgesic effects, as the administration of naloxone, a shortacting opioid antagonist in a replicate experiment, blocked the development of AM1241-mediated analgesia [164]. The involvement of endogenous opioids was further supported in mediating $\mathrm{CB}_{2} \mathrm{R}$ analgesia by an earlier study using nonneuropathic naïve rats [165]. However, Rahn and colleagues have recently demonstrated that the anti-nociceptive effects of systemic AM1241 in naïve rats are not dependent on the actions of opioid receptors or downstream effects [166]. In this study, the reported dose of AM1241 utilized by Ibrahim 


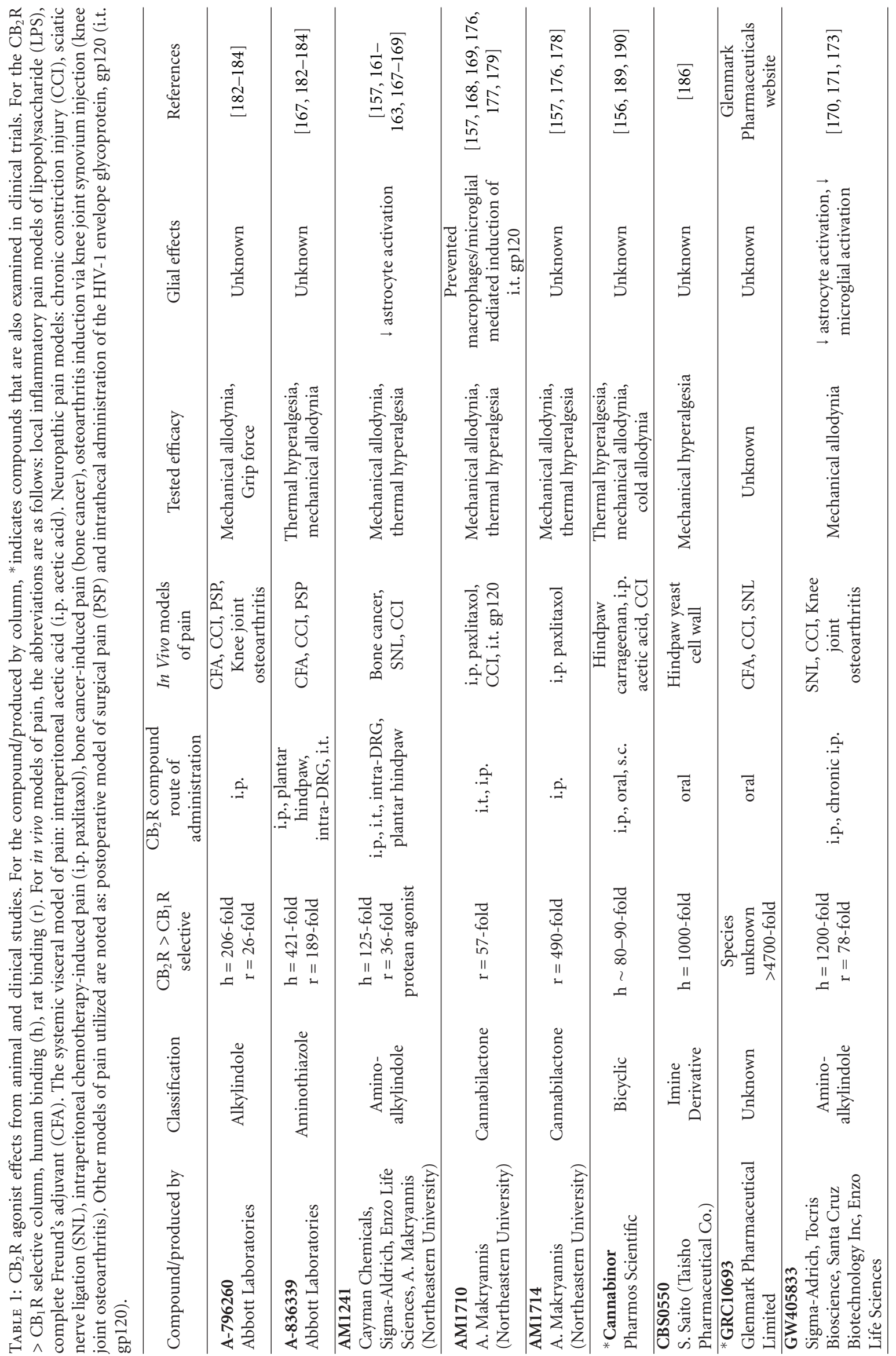




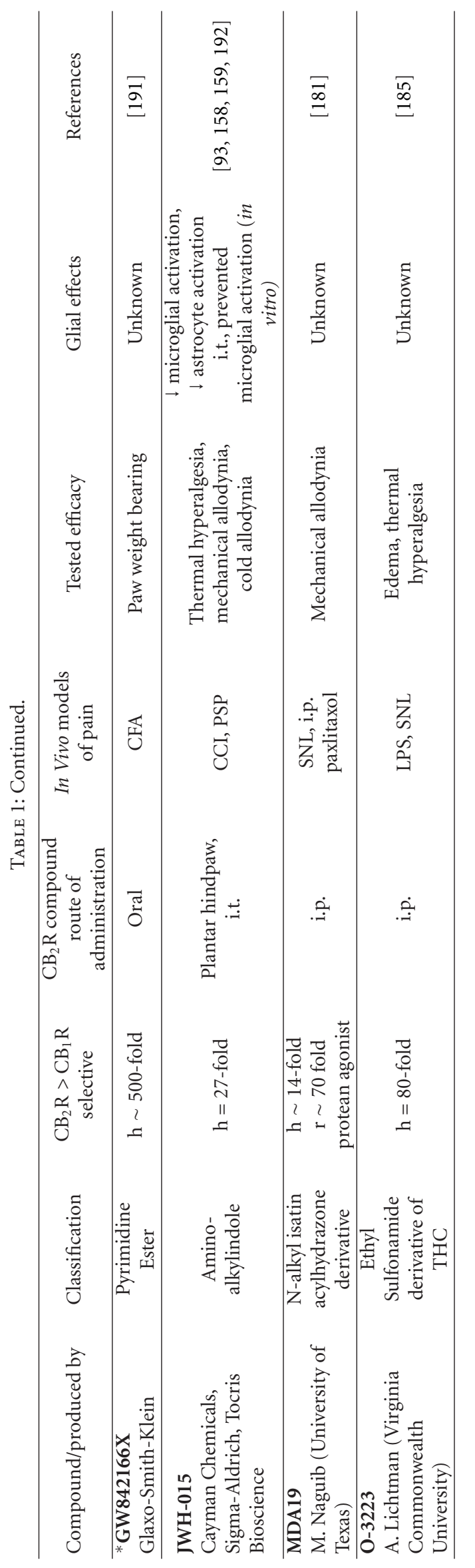


and colleagues, $0.1 \mathrm{mg} / \mathrm{kg}$ i.p, did not achieve reliable effects, and so higher doses of AM1241, up to $1 \mathrm{mg} / \mathrm{kg}$, were evaluated. Additionally, in the SNL model of neuropathic pain, the effects of AM1241 following i.p. administration were not blocked by naloxone suggesting that AM1241 does not act via opioid receptors to exert analgesic effects [167] (Table 1). The discrepancy between these studies suggests that bone cancer pain may uniquely involve endorphinendocannabinoid interactions while other discrete peripheral nerve lesions or naïve conditions may involve only the endocannabinoid system.

Spinal sensitization is a key component of chronic pathological pain. Thus, compounds developed for chronic pain control will require centrally mediated actions and may be insufficient if they do not cross the blood brain barrier because their actions will be sequestered to peripheral sites of pain processing. A growing body of evidence supports that spinal administration of AM1241 produces significant control over pathological pain in several models using peripheral manipulations. For example, intrathecal (perispinal, i.t.) AM1241 reverses allodynia induced by either SNL or intrapaw injection of complete Freund's adjuvant (CFA), a model of local inflammatory pain [167]. Additionally, i.t. AM1241 has been found to reverse CCI-induced allodynia [168] and leads to a corresponding decrease in spinal cord astrocyte activation of these previously neuropathic animals [169]. In separate studies that used SNL to induce peripheral neuropathy in rats, both astrocyte and microglial phenotypic markers of activation were decreased following either i.t. administration of JWH-015 [96] or i.p. administration of GW405833 [170], a partial $\mathrm{CB}_{2} \mathrm{R}$ agonist. Taken together, these reports demonstrate that $\mathrm{CB}_{2} \mathrm{R}$ agonists are able to alter spinal glial activation states and create in vivo antiinflammatory effects suitable for pain control.

The ability for $\mathrm{CB}_{2} \mathrm{R}$ agonists to be administered without the development of tolerance or reliance on $\mu$-opioid actions within the spinal cord has been studied utilizing GW405833. This compound is also classified as an aminoalkylindole and is additionally known as L-768,242. Conflicting reports of GW405833's affinity for the $\mathrm{CB}_{2} \mathrm{R}$ over the $\mathrm{CB}_{1} \mathrm{R}$ exist [157]. However, it is generally accepted that at the human $\mathrm{CB}_{2} \mathrm{R}$ the compound displays a 1,200-fold affinity for the $\mathrm{CB}_{2} \mathrm{R}$ over the $\mathrm{CB}_{1} \mathrm{R}$, and at the rat $\mathrm{CB}_{2} \mathrm{R}$ there is a 78fold affinity for the $\mathrm{CB}_{2} \mathrm{R}$ over the $\mathrm{CB}_{1} \mathrm{R}$ [171]. Leichsenring and colleagues recently demonstrated that chronic repeated i.p. injection of GW405833 was able to provide sustained reversal from allodynia following SNL. That is, animals did not develop tolerance to this compound, which was in stark contrast to treatment with the mixed $\mathrm{CB}_{1} \mathrm{R} / \mathrm{CB}_{2} \mathrm{R}$ agonist WIN55,212-22 [170]. Additionally, allodynia returned after intermittent treatment of GW405833. The authors also performed immunohistochemistry and, as previously noted, found diminished astrocyte and microglial activation. However, after cessation of GW405833 treatment, astrocyte and microglial activation returned, which occurred in parallel with the return of allodynia. In addition to the above mentioned benefits of $\mathrm{CB}_{2} \mathrm{R}$ agonist actions, it has recently been reported that GW405833 can reverse CCI-induced increased helplessness responses, as assessed in the forced swim test for rats, which is a model that may elucidate depression-like symptoms in animals [172]. Furthermore, GW405833 is efficacious in treating knee pain however, these studies indicate that GW405833 may have partial agonist actions at the TRPV-1 [173]. While endocannabinoids are capable of acting at the TRPV-1 receptor at high doses that subsequently lead to TRPV-1 desensitization [174, 175], the report by Schuleret and colleagues is the first electrophysiological demonstration of $\mathrm{CB}_{2} \mathrm{R}$ agonist actions on neuronal TRPV-1 ion channels. Further research is needed to understand if the downstream signaling following GW405833 binding to neuronal TRPV-1 may enhance this $\mathrm{CB}_{2} \mathrm{R}$ agonist compound's antinociceptive actions.

\section{Newer $\mathrm{CB}_{2} \mathrm{R}$ Agonist Compounds}

Several newer classes of $\mathrm{CB}_{2} \mathrm{R}$ agonists have been developed to examine therapeutic efficacy for chronic pain relief. AM1714 and AM1710 are members of the novel cannabilactone classification [157, 176]. AM1710's pharmacological profile has recently been characterized both in vitro and in vivo $[169,177]$. AM1710 does not cross the blood brain barrier and is 57-fold more selective for the $\mathrm{CB}_{2} \mathrm{R}$ over the $\mathrm{CB}_{1} \mathrm{R}$ [177]. Systemic i.p. AM1710 in naïve rats was able to produce antinociceptive mechanical responses when a 100 -fold dose range (from $0.1 \mathrm{mg} / \mathrm{kg}-$ $10 \mathrm{mg} / \mathrm{kg}$ ) was examined. At the $0.1 \mathrm{mg} / \mathrm{kg}$ dose, AM1710's effects were altered only by the administration of a $\mathrm{CB}_{2} \mathrm{R}$ antagonist, but not the administration of a $\mathrm{CB}_{1} \mathrm{R}$ antagonist. However, at the dose of $5 \mathrm{mg} / \mathrm{kg}$, both $\mathrm{CB}_{1} \mathrm{R}$ and $\mathrm{CB}_{2} \mathrm{R}$ antagonists diminished AM1710's antinociceptive actions. The doses of either $0.1 \mathrm{mg} / \mathrm{kg}$ or $10 \mathrm{mg} / \mathrm{kg}$ AM1710 did not produce behaviors typically associated with $\mathrm{CB}_{1} \mathrm{R}$ activation. This was in stark contrast to the observed $\mathrm{CB}_{1} \mathrm{R}$-induced effects from the mixed $\mathrm{CB}_{1} \mathrm{R} / \mathrm{CB}_{2} \mathrm{R}$ agonist, WIN 55,212-2. Antinociceptive effects of $5 \mathrm{mg} / \mathrm{kg}$ AM1710 were observed for as long as 120 minutes after i.p. injection, while no effects at $0.1 \mathrm{mg} / \mathrm{kg}$ were observed at the same timepoint, showing a dose effect on the duration of AM1710 efficacy [177]. In separate studies, i.t. injection of AM1710 reverses CCI-induced allodynia for approximately 3 hours [168, 169]. Additionally i.t. pretreatment with AM1710 blocks the development of allodynia in a rat model of sterile spinal cord inflammation using i.t. administration of the HIV-1 envelope glycoprotein, gp120 [168]. Separately, Rahn and colleagues have shown that AM1714 is capable of reversing chemotherapy-induced pain [178] while AM1710 prevented pain in the same model [179]. NESS400, a novel $\mathrm{CB}_{2} \mathrm{R}$ agonist, decreased spinal astrocyte and microglial activation and reversed signs of neuropathic pain behavior following i.p. administration [180]. MDA19 is also a novel $\mathrm{CB}_{2} \mathrm{R}$ agonist with moderate selectivity for the $\mathrm{CB}_{2} \mathrm{R}$ over the $\mathrm{CB}_{1} \mathrm{R}$ (approximately 14-fold) and displays properties of a protean agonist in vitro [181], like AM1241. MDA19 was found to reverse both the spinal nerve ligation and chemotherapyinduced models of chronic pain (Table 1).

Abbott Laboratories has developed two novel compounds, A-796260 and A-836339, both of which are selective 
for the $\mathrm{CB}_{2} \mathrm{R}$ over the $\mathrm{CB}_{1} \mathrm{R}$ [182-184]. A-796260, when given to rats i.p., was able to produce relief from local inflammatory pain, neuropathic pain, postoperative pain, and osteoarthritis pain. These effects were due only to the actions of the $C_{2} R$, and not $C_{1} R$ or $\mu$-opioid receptor actions, and without the development of $\mathrm{CB}_{1} \mathrm{R}$-mediated psychotropic effects. It was found in vitro that A-836339 could act as a $\mathrm{CB}_{1} \mathrm{R}$ agonist, and studies in vivo revealed that high doses of A-836339 produced $\mathrm{CB}_{1} \mathrm{R}$-mediated psychotropic effects [183]. Further studies with A-836339 reveal that this compound was also efficacious in animal models of inflammatory, neuropathic, postoperative, and osteoarthritis pain, when administered locally to the hindpaw, intra-DRG, and intrathecally. As before, the actions of A-836339 at these sites were due primarily to the $\mathrm{CB}_{2} \mathrm{R}$, and not $\mu$-opioid receptor agonism [167] (Table 1).

Several independent groups have developed and characterized additional promising $\mathrm{CB}_{2} \mathrm{R}$ selective compounds. The Lichtman laboratory has recently synthesized an ethyl sulfonamide THC analog: O-3223. This compound is also a novel $\mathrm{CB}_{2} \mathrm{R}$ agonist with a 79-fold affinity for the $\mathrm{CB}_{2} \mathrm{R}$ over the $C_{1} R$, and administration of this compound in naïve mice did not produce the psychotropic effects associated with $\mathrm{CB}_{1} \mathrm{R}$ activation [185]. In vivo antinociceptive effects of this compound were determined to be reliant on $\mathrm{CB}_{2} \mathrm{R}$, but not $\mathrm{CB}_{1} \mathrm{R}$ function. Pretreatment with i.p. O-3223 was efficacious in lowering the amount of edema in the paws of mice given the immune stimulant LPS, and i.p. O3223 reversed hyperalgesia in a mouse model of sciatic nerve ligation [185]. CBS0550 is a novel $\mathrm{CB}_{2} \mathrm{R}$ agonist with high selectivity for the $\mathrm{CB}_{2} \mathrm{R}$ and, when given orally to rats, was efficacious in reversing yeast cell-wall-induced local inflammatory pain [186]. Taken together, these studies reflect just a sample of the efforts being made toward identifying optimal $\mathrm{CB}_{2} \mathrm{R}$ compounds for pain therapeutics (Table 1).

\section{Clinical Use of $\mathrm{CB}_{2} \mathrm{R}$ Agonists}

The current clinical trials using cannabinoid compounds for the treatment of chronic pain have examined mixed $\mathrm{CB}_{1} \mathrm{R} / \mathrm{CB}_{2} \mathrm{R}$ agonists or $\mathrm{CB}_{1} \mathrm{R}$ agonists. Sativex, Marinol/ Dronabinol, and Nabilone, all containing THC derivatives, have reached late stage or regulatory approval in various countries $[187,188]$. To date, only three $\mathrm{CB}_{2} \mathrm{R}$ compounds have entered into clinical trials for human evaluation. First noted by Beltramo [156], the progress of $\mathrm{CB}_{2} \mathrm{R}$ agonists in clinical trials has not been swift. Glenmark Pharmaceuticals reported in a press release (April 13th, 2009) that its $\mathrm{CB}_{2} \mathrm{R}$ compound, GRC10693, successfully completed a phase I clinical trial, showing good tolerance and no serious adverse events in the 80 healthy patients enrolled. This safety profile of GRC10693 was observed with the highest dose of GRC10693 evaluated-1200 mg. Glenmark Pharmaceuticals states that GRC10693 shows a $\mathrm{CB}_{2} \mathrm{R}$ selectivity of $>4700$-fold over the $\mathrm{CB}_{1} \mathrm{R}$. Additionally, peripheral and oral administration of GRC10693 showed efficacy in modulating the in vivo animal models of systemic acetic acid-induced visceral pain and hindpaw carageenaninduced local inflammation, as well as CCI [189, 190]. However, the company has decided not to move forward with phase II clinical trials, as it is currently contemplating licensing the compound to other pharmaceutical companies (http://www.glenmarkpharma.cz/clin2.php?lang=en). Early clinical trials showed a safety and tolerability profile of Pharmos Scientific's Cannabinor $\mathrm{CB}_{2} \mathrm{R}$ selective compound, but it lacked reliable analgesia. Cannabinor is no longer being developed as an i.v. therapeutic (http://www.pharmoscorp .com/development/cannabinor.html). Glaxo-Smith-Klein reports numerous phase I and II trials for its $\mathrm{CB}_{2} \mathrm{R}$ agonist GW842166X. GW842166X was described as highly selective for the $C_{2} R$ over the $C B_{1} R$, with the ability to cross the blood brain barrier in animals. Additionally, this compound showed efficacy in the CFA inflammatory model of pain, without the development of tolerance [191] (Table 1). Interestingly, the only completed phase I clinical trial examined the distribution of radiolabeled GW842166X (specifically, [11c]GW842166X) via positron emission tomography (PET) analysis (http://clinicaltrials.gov/ct2/show/ NCT00511524?term=GW842166X\&rank=2). The rationale was to identify whether this compound was able to cross the blood brain barrier in 6 healthy males. All other phase I studies of this compound were terminated prior to study completion. Glaxo-Smith-Klein reports a total of 3 phase II clinical studies, all aimed at oral dosing, with all reaching completion. The first phase II study examined molar tooth extraction with enrollment in European sites. The other two studies, also with European enrollment sites, examined GW842166X efficacy in osteoarthritis pain (Table 1). Reports from these studies have not been released, and all were completed by September 2009.

The outcomes from the above-noted early clinical trials, specifically those of Cannabinor from Pharmos Scientific, suggest that there may be intrinsic differences between the cellular mechanisms within the human patient that has suffered with pain for an indeterminate amount of time. Further, intrinsic physiological differences may also exist, even in a closely monitored animal model of pain. One potential explanation may lie within the previously described spinal cord mechanisms underlying the maintenance of chronic pain. The clinical studies described did not administer these $\mathrm{CB}_{2} \mathrm{R}$ agonist compounds to the spinal cord. The restriction of these compounds to peripheral sites (i.e., poor blood brain barrier permeability) is desired to ensure that even minuscule $\mathrm{CB}_{1} \mathrm{R}$ nonspecific binding within the CNS does not occur. This is thought to be an optimal approach to avoid off-target (i.e., $\mathrm{CB}_{1} \mathrm{R}$ ) psychotropic effects. However, it may be that the administration of these compounds to reach the spinal cord is necessary to produce enduring pain relief due to the potential spinal glial mechanisms underlying chronic pathological pain. Indeed, the argument can be made that these compounds, lipophilic in nature, do possess the ability to penetrate the blood brain barrier. Additionally, it may be that these compounds, acting as very weak $\mathrm{CB}_{1} \mathrm{R}$ agonists within the CNS, at levels that do not produce psychotropic or motor side effects, are beneficial in producing pain relief. 


\section{Summary}

$\mathrm{CB}_{2} \mathrm{R}$ agonists are emerging as favorable therapeutics over $\mathrm{CB}_{1} \mathrm{R}$ for the treatment of chronic pain, as these compounds produce relief from pain symptoms without the commonly reported $\mathrm{CB}_{1} \mathrm{R}$-related side-effects, like catalepsy and motor ataxia. $\mathrm{CB}_{2} \mathrm{R}$ agonists may exert their actions independently from $\mu$-opioid receptor actions, and no evidence currently exists related to the development of tolerance or addiction following $\mathrm{CB}_{2} \mathrm{R}$ agonist administration. While $\mathrm{CB}_{2} \mathrm{R}$ agonists appear to be highly promising as a new avenue for pain therapeutics, the actual direct CNS and DRG effects of $\mathrm{CB}_{2} \mathrm{R}$ agonists on the endocannabinoid system are largely unknown. In addition, the CNS role in pain modulation of the endocannabinoid system is itself currently not fully understood and is an area of intense research. The findings discussed in this paper suggest that $\mathrm{CB}_{2} \mathrm{R}$ ligands hold promise as future therapeutics to treat chronic pain problems. However, greater research efforts are required to yield new clinically useful $\mathrm{CB}_{2} \mathrm{R}$ ligands, as the evidence and outcomes from clinical trials is limited regarding the efficacy of these compounds. Although speculative, spinal $\mathrm{CB}_{2} \mathrm{R}$ activation in humans may be necessary to reverse ongoing chronic pathological pain. This approach would preferentially target activated glia which are critical modulators of chronic neuropathic pain. Targeting glial cells, including microglial cells, with $\mathrm{CB}_{2} \mathrm{R}$ ligands may hold the key to unlocking an efficacious treatment for chronic pain patients.

\section{References}

[1] Centers for Disease Control and Prevention, Health, United States, With Special Feature on Pain, Centers for Disease Control and Prevention's (CDC) National Center for Health Statistics, 2006.

[2] C. E. Argoff, B. E. Cole, D. A. Fishbain, and G. A. Irving, "Diabetic peripheral neuropathic pain: clinical and qualityof-life issues," Mayo Clinic Proceedings, vol. 81, no. 4, supplement, pp. S3-S11, 2006.

[3] P. J. Christo and D. Mazloomdoost, "Cancer pain and analgesia," Annals of the New York Academy of Sciences, vol. 1138, pp. 278-298, 2008.

[4] C. Douglas, J. A. Wollin, and C. Windsor, "Illness and demographic correlates of chronic pain among a communitybased sample of people with multiple sclerosis," Archives of Physical Medicine and Rehabilitation, vol. 89, no. 10, pp. 1923-1932, 2008.

[5] A. S. Russell, "Quality-of-life assessment in rheumatoid arthritis," Pharmacoeconomics, vol. 26, no. 10, pp. 831-846, 2008.

[6] Y. Winter, K. Schepelmann, A. E. Spottke et al., "Healthrelated quality of life in ALS, myasthenia gravis and facioscapulohumeral muscular dystrophy," Journal of Neurology, vol. 257, no. 9, pp. 1473-1481, 2010.

[7] J. Guindon and A. G. Hohmann, "Cannabinoid CB2 receptors: a therapeutic target for the treatment of inflammatory and neuropathic pain," British Journal of Pharmacology, vol. 153, no. 2, pp. 319-334, 2008.

[8] N. Stella, "Endocannabinoid signaling in microglial cells," Neuropharmacology, vol. 56, supplement 1, pp. 244-253, 2009.
[9] A. D. Craig, "Distribution of brainstem projections from spinal lamina I neurons in the cat and the monkey," Journal of Comparative Neurology, vol. 361, no. 2, pp. 225-248, 1995.

[10] L. Villanueva and J. F. Bernard, "The multiplicity of ascending pain pathways," in Handbook of Behavioral State Control: Cellular and Molecular Mechanisms, R. Lydic and H. A. Baghdoyan, Eds., pp. 569-585, CRC Press, Boca Raton, Fla, USA, 1999.

[11] W. D. Willis and R. E. Coggeshall, Sensory Mechanisms of the Spinal Cord, Plenum Press, New York, NY, USA, 2nd edition, 1991.

[12] A. Berthele, S. J. Boxall, A. Urban et al., "Distribution and developmental changes in metabotropic glutamate receptor messenger RNA expression in the rat lumbar spinal cord," Developmental Brain Research, vol. 112, no. 1, pp. 39-53, 1999.

[13] S. N. Lawson, B. A. Crepps, and E. R. Perl, "Relationship of substance $\mathrm{P}$ to afferent characteristics of dorsal root ganglion neurones in guinea-pig," Journal of Physiology, vol. 505, part 1, pp. 177-191, 1997.

[14] S. P. Hunt and P. W. Mantyh, "The molecular dynamics of pain control," Nature Reviews Neuroscience, vol. 2, no. 2, pp. 83-91, 2001.

[15] M. Costigan, J. Scholz, and C. J. Woolf, "Neuropathic pain: a maladaptive response of the nervous system to damage," Annual Review of Neuroscience, vol. 32, pp. 1-32, 2009.

[16] C. J. Woolf and M. W. Salter, "Neuronal plasticity: increasing the gain in pain," Science, vol. 288, no. 5472, pp. 1765-1768, 2000.

[17] A. J. Cook, C. J. Woolf, P. D. Wall, and S. B. McMahon, "Dynamic receptive field plasticity in rat spinal cord dorsal horn following C-primary afferent input," Nature, vol. 325, no. 7000, pp. 151-153, 1987.

[18] P. D. Wall and C. J. Woolf, "The brief and the prolonged facilitatory effects of unmyelinated afferent input on the rat spinal cord are independently influenced by peripheral nerve section," Neuroscience, vol. 17, no. 4, pp. 1199-1205, 1986.

[19] K. M. Baumbauer, E. E. Young, and R. L. Joynes, "Pain and learning in a spinal system: contradictory outcomes from common origins," Brain Research Reviews, vol. 61, no. 2, pp. 124-143, 2009.

[20] C. Luo, P. H. Seeburg, R. Sprengel, and R. Kuner, "Activitydependent potentiation of calcium signals in spinal sensory networks in inflammatory pain states," Pain, vol. 140, no. 2, pp. 358-367, 2008.

[21] M. H. Ossipov, J. Lai, T. P. Malan, and F. Porreca, "Spinal and supraspinal mechanisms of neuropathic pain," Annals of the New York Academy of Sciences, vol. 909, pp. 12-24, 2000.

[22] R. R. Ji and C. J. Woolf, "Neuronal plasticity and signal transduction in nociceptive neurons: implications for the initiation and maintenance of pathological pain," Neurobiology of Disease, vol. 8, no. 1, pp. 1-10, 2001.

[23] D. A. Simone, T. K. Baumann, J. G. Collins, and R. H. LaMotte, "Sensitization of cat dorsal horn neurons to innocuous mechanical stimulation after intradermal injection of capsaicin," Brain Research, vol. 486, no. 1, pp. 185189, 1989.

[24] J. A. DeLeo, L. S. Sorkin, and L. R. Watkins, Eds., Immune and Glial Regulation of Pain, IASP Press, Seattle, Wash, USA, 2007.

[25] J. A. De Leo, V. L. Tawfik, and M. L. LaCroix-Fralish, "The tetrapartite synapse: path to CNS sensitization and chronic pain," Pain, vol. 122, no. 1-2, pp. 17-21, 2006. 
[26] H. Hashizume, J. A. DeLeo, R. W. Colburn, and J. N. Weinstein, "Spinal glial activation and cytokine expression after lumbar root injury in the rat," Spine, vol. 25, no. 10, pp. 1206-1217, 2000.

[27] R. R. Ji, R. W. Gereau IV, M. Malcangio, and G. R. Strichartz, "MAP kinase and pain," Brain Research Reviews, vol. 60, no. 1, pp. 135-148, 2009.

[28] A. Ledeboer, M. Gamanos, W. Lai et al., "Involvement of spinal cord nuclear factor $\kappa \mathrm{B}$ activation in rat models of proinflammatory cytokine-mediated pain facilitation," European Journal of Neuroscience, vol. 22, no. 8, pp. 19771986, 2005.

[29] E. D. Milligan and L. R. Watkins, "Pathological and protective roles of glia in chronic pain," Nature Reviews Neuroscience, vol. 10, no. 1, pp. 23-36, 2009.

[30] L. R. Watkins, M. R. Hutchinson, A. Ledeboer et al., "Norman cousins lecture. Glia as the "bad guys": implications for improving clinical pain control and the clinical utility of opioids," Brain, Behavior, and Immunity, vol. 21, no. 2, pp. 131-146, 2007.

[31] R. R. Ji and G. Strichartz, "Cell signaling and the genesis of neuropathic pain," Science's Stke, vol. 2004, no. 252, p. reE14, 2004.

[32] J. P. White, M. Cibelli, A. R. Fidalgo, and I. Nagy, "Extracellular signal-regulated kinases in pain of peripheral origin," European Journal of Pharmacology, vol. 650, no. 1, pp. 8-17, 2011.

[33] Y. J. Gao, L. Zhang, O. A. Samad et al., "JNK-induced MCP1 production in spinal cord astrocytes contributes to central sensitization and neuropathic pain," Journal of Neuroscience, vol. 29, no. 13, pp. 4096-4108, 2009.

[34] S. X. Jin, Z. Y. Zhuang, C. J. Woolf, and R. R. Ji, "p38 mitogenactivated protein kinase is activated after a spinal nerve ligation in spinal cord microglia and dorsal root ganglion neurons and contributes to the generation of neuropathic pain," Journal of Neuroscience, vol. 23, no. 10, pp. 4017-4022, 2003.

[35] H. Katsura, K. Obata, T. Mizushima et al., "Activation of Srcfamily kinases in spinal microglia contributes to mechanical hypersensitivity after nerve injury," Journal of Neuroscience, vol. 26, no. 34, pp. 8680-8690, 2006.

[36] Y. R. Wen, M. R. Suter, R. R. Ji et al., "Activation of p38 mitogen-activated protein kinase in spinal microglia contributes to incision-induced mechanical allodynia," Anesthesiology, vol. 110, no. 1, pp. 155-165, 2009.

[37] Z. Y. Zhuang, Y. R. Wen, D. R. Zhang et al., "A peptide cJun N-terminal kinase (JNK) inhibitor blocks mechanical allodynia after spinal nerve ligation: respective roles of JNK activation in primary sensory neurons and spinal astrocytes for neuropathic pain development and maintenance," Journal of Neuroscience, vol. 26, no. 13, pp. 3551-3560, 2006.

[38] J. I. Choi, C. I. Svensson, F. J. Koehrn, A. Bhuskute, and L. S. Sorkin, "Peripheral inflammation induces tumor necrosis factor dependent AMPA receptor trafficking and Akt phosphorylation in spinal cord in addition to pain behavior," Pain, vol. 149, no. 2, pp. 243-253, 2010.

[39] F. A. White, S. K. Bhangoo, and R. J. Miller, "Chemokines: integrators of pain and inflammation," Nature Reviews Drug Discovery, vol. 4, no. 10, pp. 834-844, 2005.

[40] C. L. Willis and T. P. Davis, "Chronic inflammatory pain and the neurovascular unit: a central role for glia in maintaining BBB integrity?" Current Pharmaceutical Design, vol. 14, no. 16, pp. 1625-1643, 2008.
[41] N. R. Bhat, P. Zhang, J. C. Lee, and E. L. Hogan, "Extracellular signal-regulated kinase and p38 subgroups of mitogen- activated protein kinases regulate inducible nitric oxide synthase and tumor necrosis factor- $\alpha$ gene expression in endotoxinstimulated primary glial cultures," Journal of Neuroscience, vol. 18, no. 5, pp. 1633-1641, 1998.

[42] D. Levy, A. Hoke, and D. W. Zochodne, "Local expression of inducible nitric oxide synthase in an animal model of neuropathic pain," Neuroscience Letters, vol. 260, no. 3, pp. 207-209, 1999.

[43] D. Levy and D. W. Zochodne, "NO pain: potential roles of nitric oxide in neuropathic pain," Pain Practice, vol. 4, no. 1, pp. 11-18, 2004.

[44] S. T. Meller and G. F. Gebhart, "Nitric oxide (NO) and nociceptive processing in the spinal cord," Pain, vol. 52, no. 2, pp. 127-136, 1993.

[45] J. M. Cavaillon and D. Annane, "Compartmentalization of the inflammatory response in sepsis and SIRS," Journal of Endotoxin Research, vol. 12, no. 3, pp. 151-170, 2006.

[46] T. Kato and S. Kitagawa, "Regulation of neutrophil functions by proinflammatory cytokines," International Journal of Hematology, vol. 84, no. 3, pp. 205-209, 2006.

[47] B. León and C. Ardavín, "Monocyte-derived dendritic cells in innate and adaptive immunity," Immunology and Cell Biology, vol. 86, no. 4, pp. 320-324, 2008.

[48] R. E. Simmonds and B. M. Foxwell, "Signalling, inflammation and arthritis: NF- $\kappa \mathrm{B}$ and its relevance to arthritis and inflammation," Rheumatology, vol. 47, no. 5, pp. 584-590, 2008.

[49] F. A. White, J. Sun, S. M. Waters et al., "Excitatory monocyte chemoattractant protein-1 signaling is up-regulated in sensory neurons after chronic compression of the dorsal root ganglion," Proceedings of the National Academy of Sciences of the United States of America, vol. 102, no. 39, pp. 1409214097, 2005.

[50] M. Pekny and M. Pekna, "Astrocyte intermediate filaments in CNS pathologies and regeneration," Journal of Pathology, vol. 204, no. 4, pp. 428-437, 2004.

[51] L. F. Eng, R. S. Ghirnikar, and Y. L. Lee, "Glial fibrillary acidic protein: GFAP-thirty-one years (1969-2000)," Neurochemical Research, vol. 25, no. 9-10, pp. 1439-1451, 2000.

[52] S. Echeverry, X. Q. Shi, and J. Zhang, "Characterization of cell proliferation in rat spinal cord following peripheral nerve injury and the relationship with neuropathic pain," Pain, vol. 135, no. 1-2, pp. 37-47, 2008.

[53] Y. Imai, I. Ibata, D. Ito, K. Ohsawa, and S. Kohsaka, "A novel gene ibal in the major histocompatibility complex class III region encoding an EF hand protein expressed in a monocytic lineage," Biochemical and Biophysical Research Communications, vol. 224, no. 3, pp. 855-862, 1996.

[54] S. M. McKay, D. J. Brooks, P. Hu, and E. M. McLachlan, "Distinct types of microglial activation in white and grey matter of rat lumbosacral cord after mid-thoracic spinal transection," Journal of Neuropathology and Experimental Neurology, vol. 66, no. 8, pp. 698-710, 2007.

[55] J. Mika, M. Osikowicz, E. Rojewska et al., "Differential activation of spinal microglial and astroglial cells in a mouse model of peripheral neuropathic pain," European Journal of Pharmacology, vol. 623, no. 1-3, pp. 65-72, 2009.

[56] I. Mori, Y. Imai, S. Kohsaka, and Y. Kimura, "Upregulated expression of Ibal molecules in the central nervous system of mice in response to neurovirulent influenza A virus infection," Microbiology and Immunology, vol. 44, no. 8, pp. 729-735, 2000. 
[57] K. Ohsawa, Y. Imai, H. Kanazawa, Y. Sasaki, and S. Kohsaka, "Involvement of Iba1 in membrane ruffling and phagocytosis of macrophages/microglia," Journal of Cell Science, vol. 113, part 17, pp. 3073-3084, 2000.

[58] S. K. Moestrup and H. J. Moller, "CD163: a regulated hemoglobin scavenger receptor with a role in the antiinflammatory response," Annals of Medicine, vol. 36, no. 5, pp. 347-354, 2004.

[59] F. Porcheray, S. Viaud, A. C. Rimaniol et al., "Macrophage activation switching: an asset for the resolution of inflammation," Clinical and Experimental Immunology, vol. 142, no. 3, pp. 481-489, 2005.

[60] Y. Yiangou, P. Facer, P. Durrenberger et al., "COX-2, CB2 and P2X7-immunoreactivities are increased in activated microglial cells/macrophages of multiple sclerosis and amyotrophic lateral sclerosis spinal cord," BMC Neurology, vol. 6, article 12, 2006.

[61] W. R. Yu, T. Liu, T. -R. Kiehl, and M. G. Fehlings, "Human neuropathological and animal model evidence supporting a role for Fas-mediated apoptosis and inflammation in cervical spondylotic myelopathy," Brain, vol. 134, part 5, pp. 12771292, 2011.

[62] R. J. Horvath, R. P. Landry, E. A. Romero-Sandoval, and J. A. DeLeo, "Morphine tolerance attenuates the resolution of postoperative pain and enhances spinal microglial p38 and extracellular receptor kinase phosphorylation," Neuroscience, vol. 169, no. 2, pp. 843-854, 2010.

[63] M. S. Alkaitis, C. Solorzano, R. P. Landry, D. Piomelli, J. A. DeLeo, and E. A. Romero-Sandoval, "Evidence for a role of endocannabinoids, astrocytes and p38 phosphorylation in the resolution of postoperative pain," Plos One, vol. 5, no. 5, p. e10891, 2010.

[64] E. D. Ponomarev, K. Maresz, Y. Tan, and B. N. Dittel, "CNS-derived interleukin-4 is essential for the regulation of autoimmune inflammation and induces a state of alternative activation in microglial cells," Journal of Neuroscience, vol. 27, no. 40, pp. 10714-10721, 2007.

[65] Z. Wu, J. Zhang, and H. Nakanishi, "Leptomeningeal cells activate microglia and astrocytes to induce IL-10 production by releasing pro-inflammatory cytokines during systemic inflammation," Journal of Neuroimmunology, vol. 167, no. 12, pp. 90-98, 2005.

[66] S. Kunori, S. Matsumura, E. Okuda-Ashitaka et al., "A novel role of prostaglandin E2 in neuropathic pain: blockade of microglial migration in the spinal cord," GLIA, vol. 59, no. 2, pp. 208-218, 2011.

[67] J. Wieseler-Frank, B. M. Jekich, J. H. Mahoney, S. T. Bland, S. F. Maier, and L. R. Watkins, "A novel immune-to-CNS communication pathway: cells of the meninges surrounding the spinal cord CSF space produce proinflammatory cytokines in response to an inflammatory stimulus," Brain, Behavior, and Immunity, vol. 21, no. 5, pp. 711-718, 2007.

[68] T. Rice, J. Larsen, S. Rivest, and V. W. Yong, "Characterization of the early neuroinflammation after spinal cord injury in mice," Journal of Neuropathology and Experimental Neurology, vol. 66, no. 3, pp. 184-195, 2007.

[69] M. Takeda, M. Takahashi, and S. Matsumoto, "Contribution of the activation of satellite glia in sensory ganglia to pathological pain," Neuroscience and Biobehavioral Reviews, vol. 33, no. 6, pp. 784-792, 2009.

[70] M. Hanani, "Satellite glial cells in sensory ganglia: from form to function," Brain Research Reviews, vol. 48, no. 3, pp. 457476, 2005.
[71] K. Otoshi, S. I. Kikuchi, S. I. Konno, and M. Sekiguchi, "The reactions of glial cells and endoneurial macrophages in the dorsal root ganglion and their contribution to pain-related behavior after application of nucleus pulposus onto the nerve root in rats," Spine, vol. 35, no. 3, pp. 264-271, 2010.

[72] K. Siemionow, A. Klimczak, G. Brzezicki, M. Siemionow, and R. F. McLain, "The effects of inflammation on glial fibrillary acidic protein expression in satellite cells of the dorsal root ganglion," Spine, vol. 34, no. 16, pp. 1631-1637, 2009.

[73] M. Takeda, M. Takahashi, and S. Matsumoto, "Contribution of activated interleukin receptors in trigeminal ganglion neurons to hyperalgesia via satellite glial interleukin-1 $\beta$ paracrine mechanism," Brain, Behavior, and Immunity, vol. 22, no. 7, pp. 1016-1023, 2008.

[74] R. Jancalek, P. Dubovy, I. Svizenska, and I. Klusakova, "Bilateral changes of TNF- $\alpha$ and IL-10 protein in the lumbar and cervical dorsal root ganglia following a unilateral chronic constriction injury of the sciatic nerve," Journal of Neuroinflammation, vol. 7, article 11, 2010.

[75] A. M. Skoff, C. Zhao, and J. E. Adler, "Interleukin-1 $\alpha$ regulates substance $\mathrm{P}$ expression and release in adult sensory neurons," Experimental Neurology, vol. 217, no. 2, pp. 395400, 2009.

[76] P. Dubovy, L. Tuackova, R. Janaclek, I. Svizenska, and I. Klusakova, "Increased invasion of ED-1 positive macrophages in both ipsi- and contralateral dorsal root ganglia following unilateral nerve injuries," Neuroscience Letters, vol. 427, no. 2, pp. 88-93, 2007.

[77] P. Hu, A. L. Bembrick, K. A. Keay, and E. M. McLachlan, "Immune cell involvement in dorsal root ganglia and spinal cord after chronic constriction or transection of the rat sciatic nerve," Brain, Behavior, and Immunity, vol. 21, no. 5, pp. 599616, 2007.

[78] P. Hu and E. M. McLachlan, "Macrophage and lymphocyte invasion of dorsal root ganglia after peripheral nerve lesions in the rat," Neuroscience, vol. 112, no. 1, pp. 23-38, 2002.

[79] N. Morin, S. A. Owolabi, M. W. Harty et al., "Neutrophils invade lumbar dorsal root ganglia after chronic constriction injury of the sciatic nerve," Journal of Neuroimmunology, vol. 184, no. 1-2, pp. 164-171, 2007.

[80] S. Bhangoo, D. Ren, R. J. Miller et al., "Delayed functional expression of neuronal chemokine receptors following focal nerve demyelination in the rat: a mechanism for the development of chronic sensitization of peripheral nociceptors," Molecular Pain, vol. 3, article 38, 2007.

[81] H. Jung, P. T. Toth, F. A. White, and R. J. Miller, "Monocyte chemoattractant protein-1 functions as a neuromodulator in dorsal root ganglia neurons," Journal of Neurochemistry, vol. 104, no. 1, pp. 254-263, 2008.

[82] A. M. Binshtok, H. Wang, K. Zimmermann et al., "Nociceptors are interleukin- $1 \beta$ sensors," Journal of Neuroscience, vol. 28, no. 52, pp. 14062-14073, 2008.

[83] J. C. V. M. Copray, I. Mantingh, N. Brouwer et al., "Expression of interleukin-1 $\beta$ in rat dorsal root ganglia," Journal of Neuroimmunology, vol. 118, no. 2, pp. 203-211, 2001.

[84] O. Obreja, P. K. Rathee, K. S. Lips, C. Distler, and M. Kress, "IL-1 $\beta$ potentiates heat-activated currents in rat sensory neurons: involvement of IL-1RI, tyrosine kinase, and protein kinase C," Faseb Journal, vol. 16, no. 12, pp. 1497-1503, 2002.

[85] A. Inoue, K. Ikoma, N. Morioka et al., "Interleukin- $1 \beta$ induces substance $\mathrm{P}$ release from primary afferent neurons through the cyclooxygenase-2 system," Journal of Neurochemistry, vol. 73, no. 5, pp. 2206-2213, 1999. 
[86] R. R. Ji, T. A. Samad, S. X. Jin, R. Schmoll, and C. J. Woolf, "p38 MAPK activation by NGF in primary sensory neurons after inflammation increases TRPV1 levels and maintains heat hyperalgesia," Neuron, vol. 36, no. 1, pp. 57-68, 2002.

[87] J. T. Xu, W. J. Xin, X. H. Wei et al., "p38 activation in uninjured primary afferent neurons and in spinal microglia contributes to the development of neuropathic pain induced by selective motor fiber injury," Experimental Neurology, vol. 204, no. 1, pp. 355-365, 2007.

[88] L. R. Watkins and S. F. Maier, "Targeting glia to control clinical pain: an idea whose time has come," Drug Discovery Today: Therapeutic Strategies, vol. 1, no. 1, pp. 83-88, 2004.

[89] A. Ledeboer, E. M. Sloane, E. D. Milligan et al., "Minocycline attenuates mechanical allodynia and proinflammatory cytokine expression in rat models of pain facilitation," Pain, vol. 115, no. 1-2, pp. 71-83, 2005.

[90] Y. W. Chang and S. G. Waxman, "Minocycline attenuates mechanical allodynia and central sensitization following peripheral second-degree burn injury," Journal of Pain, vol. 11, no. 11, pp. 1146-1154, 2010.

[91] C. C. Liu, N. Lu, Y. Cui et al., "Prevention of paclitaxelinduced allodynia by minocycline: effect on loss of peripheral nerve fibers and infiltration of macrophages in rats," Molecular Pain, vol. 6, article 76, 2010.

[92] F. Giuliani, W. Hader, and V. W. Yong, "Minocycline attenuates $\mathrm{T}$ cell and microglia activity to impair cytokine production in T cell-microglia interaction," Journal of Leukocyte Biology, vol. 78, no. 1, pp. 135-143, 2005.

[93] E. A. Romero-Sandoval, R. Horvath, R. P. Landry, and J. A. DeLeo, "Cannabinoid receptor type 2 activation induces a microglial anti-inflammatory phenotype and reduces migration via MKP induction and ERK dephosphorylation," Molecular Pain, vol. 5, article 25, 2009.

[94] L. Walter, A. Franklin, A. Witting et al., "Nonpsychotropic cannabinoid receptors regulate microglial cell migration," Journal of Neuroscience, vol. 23, no. 4, pp. 1398-1405, 2003.

[95] I. Racz, X. Nadal, J. Alferink et al., "Crucial role of CB2 cannabinoid receptor in the regulation of central immune responses during neuropathic pain," Journal of Neuroscience, vol. 28, no. 46, pp. 12125-12135, 2008.

[96] A. Romero-Sandoval, N. Nutile-Mcmenemy, and J. A. Deleo, "Spinal microglial and perivascular cell cannabinoid receptor type 2 activation reduces behavioral hypersensitivity without tolerance after peripheral nerve injury," Anesthesiology, vol. 108, no. 4, pp. 722-734, 2008.

[97] A. Calignano, G. La Rana, A. Giuffrida, and D. Piomelli, "Control of pain initiation by endogenous cannabinoids," Nature, vol. 394, no. 6690, pp. 277-281, 1998.

[98] J. D. Richardson, L. Aanonsen, and K. M. Hargreaves, "Antihyperalgesic effects of spinal cannabinoids," European Journal of Pharmacology, vol. 345, no. 2, pp. 145-153, 1998.

[99] J. D. Richardson, S. Kilo, and K. M. Hargreaves, "Cannabinoids reduce hyperalgesia and inflammation via interaction with peripheral CB1 receptors," Pain, vol. 75, no. 1, pp. 111119, 1998.

[100] A. Moriconi, I. Cerbara, M. Maccarrone, and A. Topai, "GPR55: current knowledge and future perspectives of a purported "type-3" cannabinoid receptor," Current Medicinal Chemistry, vol. 17, no. 14, pp. 1411-1429, 2010.

[101] D. G. Johns, D. J. Behm, D. J. Walker et al., "The novel endocannabinoid receptor GPR55 is activated by atypical cannabinoids but does not mediate their vasodilator effects," British Journal of Pharmacology, vol. 152, no. 5, pp. 825-831, 2007.
[102] J. E. Lauckner, J. B. Jensen, H. Y. Chen, H. C. Lu, B. Hille, and K. Mackie, "GPR55 is a cannabinoid receptor that increases intracellular calcium and inhibits M current," Proceedings of the National Academy of Sciences of the United States of America, vol. 105, no. 7, pp. 2699-2704, 2008.

[103] S. Oka, K. Nakajima, A. Yamashita, S. Kishimoto, and T. Sugiura, "Identification of GPR55 as a lysophosphatidylinositol receptor," Biochemical and Biophysical Research Communications, vol. 362, no. 4, pp. 928-934, 2007.

[104] E. Ryberg, N. Larsson, S. Sjogren et al., "The orphan receptor GPR55 is a novel cannabinoid receptor," British Journal of Pharmacology, vol. 152, no. 7, pp. 1092-1101, 2007.

[105] E. Kotsikorou, D. L. Lynch, M. E. Abood, and P. H. Reggio, "Lipid bilayer molecular dynamics study of lipid-derived agonists of the putative cannabinoid receptor, GPR55," Chemistry and Physics of Lipids, vol. 164, no. 2, pp. 131-143, 2011.

[106] H. Sharir and M. E. Abood, "Pharmacological characterization of GPR55, a putative cannabinoid receptor," Pharmacology and Therapeutics, vol. 126, no. 3, pp. 301-313, 2010.

[107] P. C. Staton, J. P. Hatcher, D. J. Walker et al., "The putative cannabinoid receptor GPR55 plays a role in mechanical hyperalgesia associated with inflammatory and neuropathic pain," Pain, vol. 139, no. 1, pp. 225-236, 2008.

[108] A. C. Howlett, "Cannabinoid receptor signaling," Handbook of Experimental Pharmacology, no. 168, pp. 53-79, 2005.

[109] S. Mitrirattanakul, N. Ramakul, A. V. Guerrero et al., "Sitespecific increases in peripheral cannabinoid receptors and their endogenous ligands in a model of neuropathic pain," Pain, vol. 126, no. 1-3, pp. 102-114, 2006.

[110] I. Svizenska, P. Dubovy, and A. Sulcova, "Cannabinoid receptors 1 and 2 (CB1 and $\mathrm{CB} 2$ ), their distribution, ligands and functional involvement in nervous system structures-a short review," Pharmacology Biochemistry and Behavior, vol. 90, no. 4, pp. 501-511, 2008.

[111] S. Munro, K. L. Thomas, and M. Abu-Shaar, "Molecular characterization of a peripheral receptor for cannabinoids," Nature, vol. 365, no. 6441, pp. 61-65, 1993.

[112] M. Bouaboula, M. Rinaldi, P. Carayon et al., "Cannabinoidreceptor expression in human leukocytes," European Journal of Biochemistry, vol. 214, no. 1, pp. 173-180, 1993.

[113] S. Galiegue, S. Mary, J. Marchand et al., "Expression of central and peripheral cannabinoid receptors in human immune tissues and leukocyte subpopulations," European Journal of Biochemistry, vol. 232, no. 1, pp. 54-61, 1995.

[114] M. Bouaboula, C. Poinot-Chazel, J. Marchand et al., "Signaling pathway associated with stimulation of CB2 peripheral cannabinoid receptor: involvement of both mitogenactivated protein kinase and induction of Krox-24 expression," European Journal of Biochemistry, vol. 237, no. 3, pp. 704-711, 1996.

[115] D. M. Slipetz, G. P. O’Neill, L. Favreau et al., "Activation of the human peripheral cannabinoid receptor results in inhibition of adenylyl cyclase," Molecular Pharmacology, vol. 48, no. 2, pp. 352-361, 1995.

[116] M. Bidaut-Russell, W. A. Devane, and A. C. Howlett, "Cannabinoid receptors and modulation of cyclic AMP accumulation in the rat brain," Journal of Neurochemistry, vol. 55 , no. 1, pp. 21-26, 1990.

[117] A. C. Howlett, "Cannabinoid inhibition of adenylate cyclase. Biochemistry of the response in neuroblastoma cell membranes," Molecular Pharmacology, vol. 27, no. 4, pp. 429-436, 1985. 
[118] K. Mackie and B. Hille, "Cannabinoids inhibit N-type calcium channels in neuroblastoma-glioma cells," Proceedings of the National Academy of Sciences of the United States of America, vol. 89, no. 9, pp. 3825-3829, 1992.

[119] J. Liu, B. Gao, F. Mirshahi et al., "Functional CB1 cannabinoid receptors in human vascular endothelial cells," Biochemical Journal, vol. 346, no. 3, pp. 835-840, 2000.

[120] D. Rueda, I. Galve-Roperh, A. Haro, and M. Guzman, "The $\mathrm{CB} 1$ cannabinoid receptor is coupled to the activation of cjun N-terminal kinase," Molecular Pharmacology, vol. 58, no. 4, pp. 814-820, 2000.

[121] T. Y. Jen, G. A. Hughes, and H. Smith, "Total synthesis of $\Delta 8-(\Delta 1(6))$-tetrahydrocannabinol, a biologically active constituent of hashish (marijuana)," Journal of the American Chemical Society, vol. 89, no. 17, pp. 4551-4552, 1967.

[122] R. Mechoulam and Y. Gaoni, "A total synthesis of dl- $\Delta 1-$ tetrahydrocannabinol, the active constituent of hashish," Journal of the American Chemical Society, vol. 87, no. 14, pp. 3273-3275, 1965.

[123] R. Mechoulam and Y. Gaoni, "Hashish-IV. The isolation and structure of cannabinolic cannabidiolic and cannabigerolic acids," Tetrahedron, vol. 21, no. 5, pp. 1223-1229, 1965.

[124] R. E. Blair, L. S. Deshpande, S. Sombati, M. R. Elphick, B. R. Martin, and R. J. DeLorenzo, "Prolonged exposure to WIN55,212-2 causes downregulation of the CB1 receptor and the development of tolerance to its anticonvulsant effects in the hippocampal neuronal culture model of acquired epilepsy," Neuropharmacology, vol. 57, no. 3, pp. 208-218, 2009.

[125] A. C. Howlett, "Pharmacology of cannabinoid receptors," Annual Review of Pharmacology and Toxicology, vol. 35, pp. 607-634, 1995.

[126] A. V. Goonawardena, G. Riedel, and R. E. Hampson, "Cannabinoids alter spontaneous firing, bursting, and cell synchrony of hippocampal principal cells," Hippocampus, vol. 21, no. 5, pp. 520-531, 2011.

[127] P. K. Chanda, Y. Gao, L. Mark et al., "Monoacylglycerol lipase activity is a critical modulator of the tone and integrity of the endocannabinoid system," Molecular Pharmacology, vol. 78, no. 6, pp. 996-1003, 2010.

[128] K. Hayakawa, K. Mishima, M. Hazekawa et al., "Cannabidiol potentiates pharmacological effects of $\Delta 9$-tetrahydrocannabinol via CB1 receptor-dependent mechanism," Brain Research, vol. 1188, no. 1, pp. 157-164, 2008.

[129] J. E. Schlosburg, J. L. Blankman, J. Z. Long et al., "Chronic monoacylglycerol lipase blockade causes functional antagonism of the endocannabinoid system," Nature Neuroscience, vol. 13, no. 9, pp. 1113-1119, 2010.

[130] R. E. Hampson and S. A. Deadwyler, "Cannabinoids reveal the necessity of hippocampal neural encoding for short-term memory in rats," Journal of Neuroscience, vol. 20, no. 23, pp. 8932-8942, 2000.

[131] L. Robinson, S. McKillop-Smith, N. L. Ross et al., "Hippocampal endocannabinoids inhibit spatial learning and limit spatial memory in rats," Psychopharmacology, vol. 198, no. 4, pp. 551-563, 2008.

[132] R. G. Pertwee, "The diverse CB1 and CB2 receptor pharmacology of three plant cannabinoids: $\Delta 9$-tetrahydrocannabinol, cannabidiol and $\Delta 9$-tetrahydrocannabivarin," British Journal of Pharmacology, vol. 153, no. 2, pp. 199-215, 2008.

[133] C. C. Toth, N. M. Jedrzejewski, C. L. Ellis, and W. H. Frey, "Cannabinoid-mediated modulation of neuropathic pain and microglial accumulation in a model of murine type I diabetic peripheral neuropathic pain," Molecular Pain, vol. 6, p. 16, 2010.

[134] K. Chopra, V. Tiwari, V. Arora, and A. Kuhad, "Sesamol suppresses neuro-inflammatory cascade in experimental model of diabetic neuropathy," Journal of Pain, vol. 11, no. 10, pp. 950-957, 2010.

[135] A. Dogrul, H. Gul, O. Yesilyurt, U. H. Ulas, and O. Yildiz, "Systemic and spinal administration of etanercept, a tumor necrosis factor $\alpha$ inhibitor, blocks tactile allodynia in diabetic mice," Acta Diabetologica, pp. 1-8, 2010.

[136] S. Talbot, E. Chahmi, J. P. Dias, and R. Couture, "Key role for spinal dorsal horn microglial kinin B1 receptor in early diabetic pain neuropathy," Journal of Neuroinflammation, vol. 7, no. 1, article 36, 2010.

[137] S. J. Carlisle, F. Marciano-Cabral, A. Staab, C. Ludwick, and G. A. Cabral, "Differential expression of the CB2 cannabinoid receptor by rodent macrophages and macrophage-like cells in relation to cell activation," International Immunopharmacology, vol. 2, no. 1, pp. 69-82, 2002.

[138] J. Zhang, C. Hoffert, H. K. Vu, T. Groblewski, S. Ahmad, and D. O'Donnell, "Induction of CB2 receptor expression in the rat spinal cord of neuropathic but not inflammatory chronic pain models," European Journal of Neuroscience, vol. 17, no. 12, pp. 2750-2754, 2003.

[139] G. Wotherspoon, A. Fox, P. McIntyre, S. Colley, S. Bevan, and J. Winter, "Peripheral nerve injury induces cannabinoid receptor 2 protein expression in rat sensory neurons," Neuroscience, vol. 135, no. 1, pp. 235-245, 2005.

[140] Q. R. Liu, C. H. Pan, A. Hishimoto et al., "Species differences in cannabinoid receptor 2 (CNR2 gene): identification of novel human and rodent $\mathrm{CB} 2$ isoforms, differential tissue expression and regulation by cannabinoid receptor ligands," Genes, Brain and Behavior, vol. 8, no. 5, pp. 519-530, 2009.

[141] J. L. Blankman, G. M. Simon, and B. F. Cravatt, "A comprehensive profile of brain enzymes that hydrolyze the endocannabinoid 2-arachidonoylglycerol," Chemistry and Biology, vol. 14, no. 12, pp. 1347-1356, 2007.

[142] A. I. Gulyas, B. F. Cravatt, M. H. Bracey et al., "Segregation of two endocannabinoid-hydrolyzing enzymes into preand postsynaptic compartments in the rat hippocampus, cerebellum and amygdala," European Journal of Neuroscience, vol. 20, no. 2, pp. 441-458, 2004.

[143] M. K. McKinney and B. E. Cravatt, "Structure and function of fatty acid amide hydrolase," Annual Review of Biochemistry, vol. 74, pp. 411-432, 2005.

[144] T. P. Dinh, T. F. Freund, and D. Piomelli, "A role for monoglyceride lipase in 2-arachidonoylglycerol inactivation," Chemistry and Physics of Lipids, vol. 121, no. 1-2, pp. 149-158, 2002.

[145] A. Witting, L. Walter, J. Wacker, T. Moller, and N. Stella, "P2X7 receptors control 2-arachidonoylglycerol production by microglial cells," Proceedings of the National Academy of Sciences of the United States of America, vol. 101, no. 9, pp. 3214-3219, 2004.

[146] G. G. Muccioli, C. Xu, E. Odah et al., "Identification of a novel endocannabinoid-hydrolyzing enzyme expressed by microglial cells," Journal of Neuroscience, vol. 27, no. 11, pp. 2883-2889, 2007.

[147] I. J. Lever, M. Robinson, M. Cibelli et al., "Localization of the endocannabinoid-degrading enzyme fatty acid amide hydrolase in rat dorsal root ganglion cells and its regulation after peripheral nerve injury," Journal of Neuroscience, vol. 29, no. 12, pp. 3766-3780, 2009. 
[148] G. Horvath, G. Kekesi, E. Nagy, and G. Benedek, "The role of TRPV1 receptors in the antinociceptive effect of anandamide at spinal level," Pain, vol. 134, no. 3, pp. 277-284, 2008.

[149] J. Guindon, J. Desroches, and P. Beaulieu, "The antinociceptive effects of intraplantar injections of 2-arachidonoyl glycerol are mediated by cannabinoid CB2 receptors," British Journal of Pharmacology, vol. 150, no. 6, pp. 693-701, 2007.

[150] J. Guindon, A. Guijarro, D. Piomelli, and A. G. Hohmann, "Peripheral antinociceptive effects of inhibitors of monoacylglycerol lipase in a rat model of inflammatory pain," British Journal of Pharmacology, vol. 163, no. 7, pp. 1464-1478, 2011.

[151] C. Potenzieri, T. S. Brink, and D. A. Simone, "Excitation of cutaneous $\mathrm{C}$ nociceptors by intraplantar administration of anandamide," Brain Research, vol. 1268, pp. 38-47, 2009.

[152] S. G. Kinsey, J. Z. Long, S. T. O’Neal et al., "Blockade of endocannabinoid-degrading enzymes attenuates neuropathic pain," Journal of Pharmacology and Experimental Therapeutics, vol. 330, no. 3, pp. 902-910, 2009.

[153] J. Z. Long, D. K. Nomura, R. E. Vann et al., "Dual blockade of FAAH and MAGL identifies behavioral processes regulated by endocannabinoid crosstalk in vivo," Proceedings of the National Academy of Sciences of the United States of America, vol. 106, no. 48, pp. 20270-20275, 2009.

[154] D. R. Sagar, A. G. Gaw, B. N. Okine et al., "Dynamic regulation of the endocannabinoid system: implications for analgesia," Molecular pain, vol. 5, p. 59, 2009.

[155] D. Piomelli, "The molecular logic of endocannabinoid signalling," Nature Reviews Neuroscience, vol. 4, no. 11, pp. 873-884, 2003.

[156] M. Beltramo, "Cannabinoid type 2 receptor as a target for chronic_pain," Mini-Reviews in Medicinal Chemistry, vol. 9, no. 1, pp. 11-25, 2009.

[157] G. A. Thakur, R. Tichkule, S. Bajaj, and A. Makriyannis, "Latest advances in cannabinoid receptor agonists," Expert Opinion on Therapeutic Patents, vol. 19, no. 12, pp. 1647$1673,2009$.

[158] S. M. Huang, T. Bisogno, T. J. Petros et al., "Identification of a new class of molecules, the arachidonyl amino acids, and characterization of one member that inhibits pain," Journal of Biological Chemistry, vol. 276, no. 46, pp. 42639-42644, 2001.

[159] V. M. Showalter, D. R. Compton, B. R. Martin, and M. E. Abood, "Evaluation of binding in a transfected cell line expressing a peripheral cannabinoid receptor (CB2): identification of cannabinoid receptor subtype selective ligands," Journal of Pharmacology and Experimental Therapeutics, vol. 278, no. 3, pp. 989-999, 1996.

[160] S. M. Keyse, "Dual-specificity MAP kinase phosphatases (MKPs) and cancer," Cancer and Metastasis Reviews, vol. 27, no. 2, pp. 253-261, 2008.

[161] S. Mukherjee, M. Adams, K. Whiteaker et al., "Species comparison and pharmacological characterization of rat and human CB2 cannabinoid receptors," European Journal of Pharmacology, vol. 505, no. 1-3, pp. 1-9, 2004.

[162] B. B. Yao, S. Mukherjee, Y. Fan et al., "In vitro pharmacological characterization of AM1241: a protean agonist at the cannabinoid CB2 receptor?" British Journal of Pharmacology, vol. 149, no. 2, pp. 145-154, 2006.

[163] A. N. Lozano-Ondoua, C. Wright, A. Vardanyan et al., "A cannabinoid 2 receptor agonist attenuates bone cancerinduced pain and bone loss," Life Sciences, vol. 86, no. 17-18, pp. 646-653, 2010.

[164] V. Curto-Reyes, S. Llames, A. Hidalgo, L. Menendez, and A. Baamonde, "Spinal and peripheral analgesic effects of the CB2 cannabinoid receptor agonist AM1241 in two models of bone cancer-induced pain," British Journal of Pharmacology, vol. 160, no. 3, pp. 561-573, 2010.

[165] M. M. Ibrahim, F. Porreca, J. Lai et al., "CB2 cannabinoid receptor activation produces antinociception by stimulating peripheral release of endogenous opioids," Proceedings of the National Academy of Sciences of the United States of America, vol. 102, no. 8, pp. 3093-3098, 2005.

[166] E. J. Rahn, A. M. Zvonok, A. Makriyannis, and A. G. Hohmann, "Antinociceptive effects of racemic AM1241 and its chirally synthesized enantiomers: lack of dependence upon opioid receptor activation," AAPS Journal, vol. 12, no. 2, pp. 147-157, 2010.

[167] G. C. Hsieh, M. Pai, P. Chandran et al., "Central and peripheral sites of action for $\mathrm{CB} 2$ receptor mediated analgesic activity in chronic inflammatory and neuropathic pain models in rats," British Journal of Pharmacology, vol. 162, no. 2, pp. 428-440, 2011.

[168] J. L. Wilkerson et al., Cannabinoid 2 Receptor (CB2R) Selective Agonists Given Intrathecally Reverse Chronic Constriction Injury (CCI)-Induced Allodynia in Society for Neuroscience, Chicago, Ill, USA, 2009.

[169] J. L. Wilkerson et al., Selective Cannabinoid Receptor 2 (CB2) Agonists Administered Intrathecally Act as Indirect Agonists to Differentially Alter p38 MAPK Production in the Spinal Cord and Dorsal Root Ganglion in Neuropathic Rats in Society of Neuroscience, San Diego, Calif, USA, 2010.

[170] A. Leichsenring, M. Andriske, I. Backer, C. C. Stichel, and H. Lubbert, "Analgesic and antiinflammatory effects of cannabinoid receptor agonists in a rat model of neuropathic pain," Naunyn-Schmiedeberg's Archives of Pharmacology, vol. 379, no. 6, pp. 627-636, 2009.

[171] K. J. Valenzano, L. Tafesse, G. Lee et al., "Pharmacological and pharmacokinetic characterization of the cannabinoid receptor 2 agonist, GW405833, utilizing rodent models of acute and chronic pain, anxiety, ataxia and catalepsy," Neuropharmacology, vol. 48, no. 5, pp. 658-672, 2005.

[172] B. Hu, H. Doods, R. D. Treede, and A. Ceci, "Depressionlike behaviour in rats with mononeuropathy is reduced by the CB2-selective agonist GW405833," Pain, vol. 143, no. 3, pp. 206-212, 2009.

[173] N. Schuelert, C. Zhang, A. J. Mogg et al., "Paradoxical effects of the cannabinoid CB2 receptor agonist GW405833 on rat osteoarthritic knee joint pain," Osteoarthritis and Cartilage, vol. 18, no. 11, pp. 1536-1543, 2010.

[174] K. Alawi and J. Keeble, "The paradoxical role of the transient receptor potential vanilloid 1 receptor in inflammation," Pharmacology and Therapeutics, vol. 125, no. 2, pp. 181-195, 2010.

[175] T. Hagenacker, D. Ledwig, and D. Busselberg, "Feedback mechanisms in the regulation of intracellular calcium $([\mathrm{Ca} 2+] \mathrm{i})$ in the peripheral nociceptive system: role of TRPV1 and pain related receptors," Cell Calcium, vol. 43, no. 3, pp. 215-227, 2008.

[176] A. D. Khanolkar, D. Lu, M. Ibrahim et al., "Cannabilactones: a novel class of CB2 selective agonists with peripheral analgesic activity," Journal of Medicinal Chemistry, vol. 50, no. 26, pp. 6493-6500, 2007.

[177] E. J. Rahn, G. A. Thakur, J. A. Wood, A. M. Zvonok, A. Makriyannis, and A. G. Hohmann, "Pharmacological characterization of AM1710, a putative cannabinoid CB 2 agonist from the cannabilactone class: antinociception without central nervous system side-effects," Pharmacology Biochemistry and Behavior, vol. 98, no. 4, pp. 493-502, 2011. 
[178] E. J. Rahn, A. M. Zvonok, G. A. Thakur, A. D. Khanolkar, A. Makriyannis, and A. G. Hohmann, "Selective activation of cannabinoid $\mathrm{CB} 2$ receptors suppresses neuropathic nociception induced by treatment with the chemotherapeutic agent paclitaxel in rats," Journal of Pharmacology and Experimental Therapeutics, vol. 327, no. 2, pp. 584-591, 2008.

[179] E. J. Rahn, G. A. Thakur, V. k. Vemuri et al., Prophylactic Treatment with Cannabinoids Suppresses the Development of Neuropathic Nociception Resulting from Treatment with the Chemotherapeutic Agent Paclitaxel in Rats in Society for Neuroscience, San Diego, Calif, USA, 2010.

[180] L. Luongo, E. Palazzo, S. Tambaro et al., “1-(2',4'dichlorophenyl)-6-methyl-N-cyclohexylamine-1,4-dihy droindeno[1,2-c]pyrazole-3-carboxamide, a novel CB2 agonist, alleviates neuropathic pain through functional microglial changes in mice," Neurobiology of Disease, vol. 37, no. 1, pp. 177-185, 2010.

[181] J. J. Xu, P. Diaz, F. Astruc-Diaz, S. Craig, E. Munoz, and M. Naguib, "Pharmacological characterization of a novel cannabinoid ligand, MDA19, for treatment of neuropathic pain," Anesthesia and Analgesia, vol. 111, no. 1, pp. 99-109, 2010.

[182] J. M. Frost, M. J. Dart, K. R. Tietje et al., "Indol-3yl-tetramethylcyclopropyl ketones: effects of indole ring substitution on CB2 cannabinoid receptor activity," Journal of Medicinal Chemistry, vol. 51, no. 6, pp. 1904-1912, 2008.

[183] B. B. Yao, G. Hsieh, A. V. Daza et al., "Characterization of a cannabinoid CB2 receptor-selective agonist, A-836339 [2,2,3,3-tetramethyl-cyclopropanecarboxylic acid [3-(2methoxy-ethyl)-4,5-dimethyl-3H-thiazol-(2Z)-ylidene]Amide], using in vitro pharmacological assays, in vivo pain models, and pharmacological magnetic resonance imaging," Journal of Pharmacology and Experimental Therapeutics, vol. 328, no. 1, pp. 141-151, 2009.

[184] B. B. Yao, G. C. Hsieh, J. M. Frost et al., "In vitro and in vivo characterization of A-796260: a selective cannabinoid CB2 receptor agonist exhibiting analgesic activity in rodent pain models," British Journal of Pharmacology, vol. 153, no. 2, pp. 390-401, 2008.

[185] S. G. Kinsey, A. Mahadevan, B. Zhao et al., "The CB2 cannabinoid receptor-selective agonist $\mathrm{O}-3223$ reduces pain and inflammation without apparent cannabinoid behavioral effects," Neuropharmacology, vol. 60, no. 2-3, pp. 244-251, 2011.

[186] H. Ohta, T. Ishizaka, M. Tatsuzuki et al., "Imine derivatives as new potent and selective CB2 cannabinoid receptor agonists with an analgesic action," Bioorganic and Medicinal Chemistry, vol. 16, no. 3, pp. 1111-1124, 2008.

[187] A. Gardin, K. Kucher, B. Kiese, and S. Appel-Dingemanse, "Cannabinoid receptor agonist 13, a novel cannabinoid agonist: first in human pharmacokinetics and safety," Drug Metabolism and Disposition, vol. 37, no. 4, pp. 827-833, 2009.

[188] R. D. Hosking and J. P. Zajicek, "Therapeutic potential of cannabis in pain medicine," British Journal of Anaesthesia, vol. 101, no. 1, pp. 59-68, 2008.

[189] A. F. Bar-Joseph, G. Richstein, A. Dar et al., "PRS-211,375, a novel selective $\mathrm{CB} 2$ receptor agonist, demonstrates analgesic activity in several animal models. Program No. 909.05," in Proceedings of the Neuroscience Meeting Planner, Society for Neuroscience, New Orleans, La, USA, 2003.

[190] A. M. Bar-Joseph, S. Eliav, E. Weksler et al., "PRS-211,375, a novel CB2 selective cannabinoid receptor agonist demonstrates analgesic activity in two neuropathic pain models.
Program No. 225.12," in Proceedings of the Neuroscience Meeting Planner, Society for Neuroscience, San Diego, Calif, USA, 2004.

[191] G. M. Giblin, C. T. O'Shaughnessy, A. Naylor et al., "Discovery of 2-[(2,4-dichlorophenyl)amino]-N-[(tetrahydro-2H-pyran-4-yl) methyl]-4-(trifluoromethyl)-5-pyrimidinecarboxamide, a selective CB2 receptor agonist for the treatment of inflammatory pain," Journal of Medicinal Chemistry, vol. 50, no. 11, pp. 2597-2600, 2007.

[192] A. Hervera, R. Negrete, S. Leánez et al., "The role of nitric oxide in the local antiallodynic and antihyperalgesic effects and expression of delta-opioid and cannabinoid- 2 receptors during neuropathic pain in mice," Journal of Pharmacology and Experimental Therapeutics, vol. 334, no. 3, pp. 887-896, 2010. 


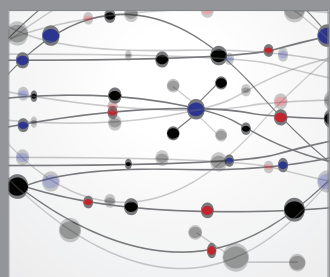

The Scientific World Journal
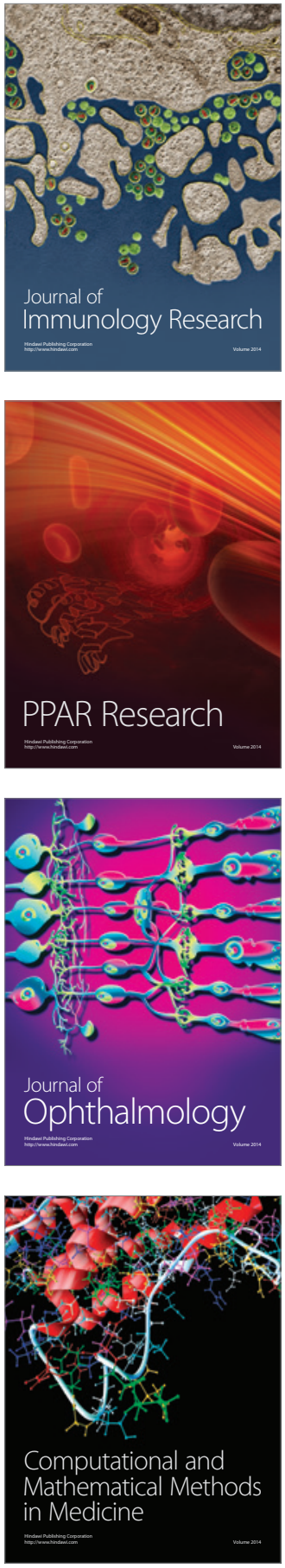

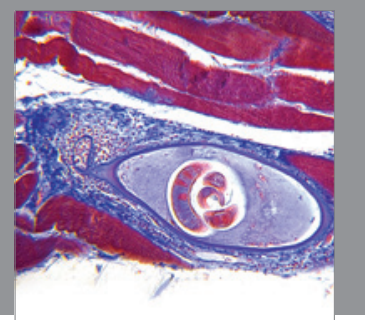

Gastroenterology

Research and Practice
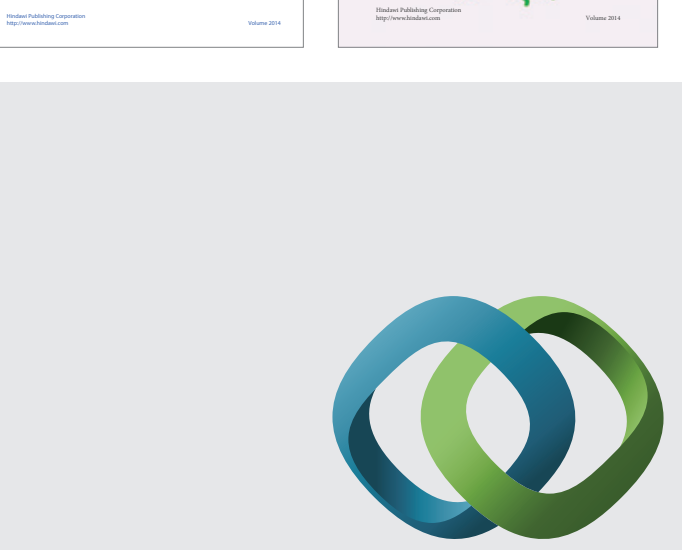

\section{Hindawi}

Submit your manuscripts at

http://www.hindawi.com
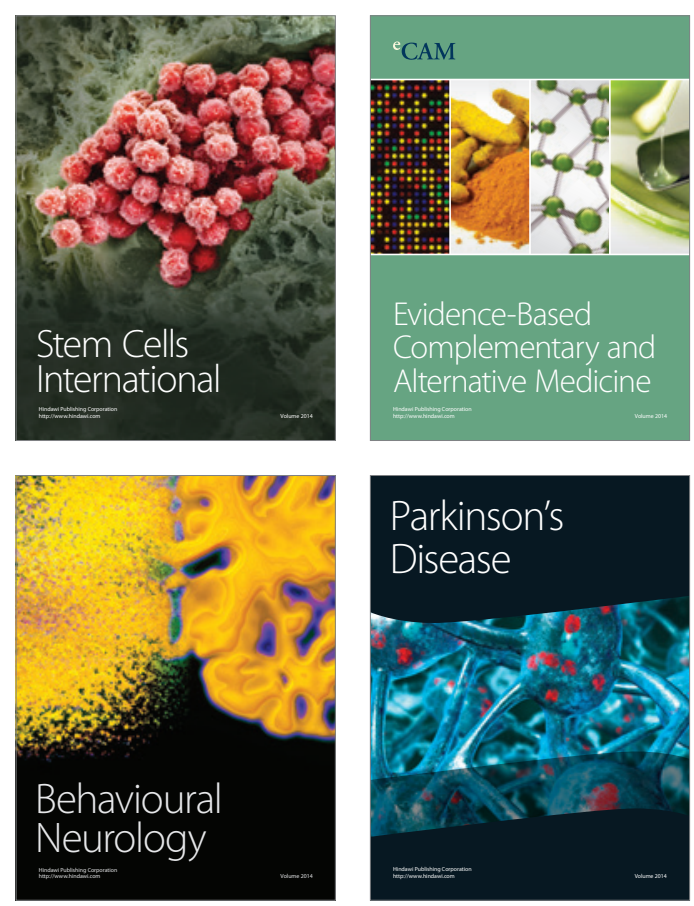

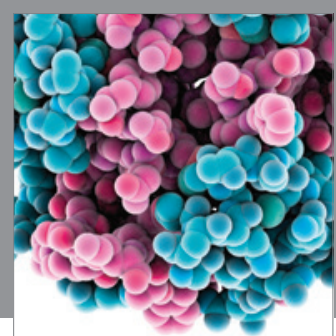

Journal of
Diabetes Research

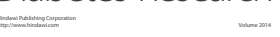

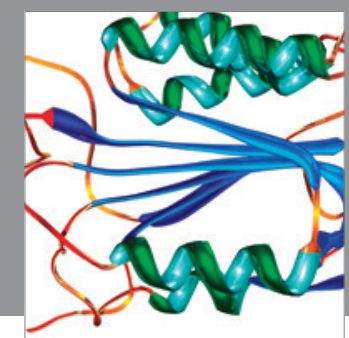

Disease Markers
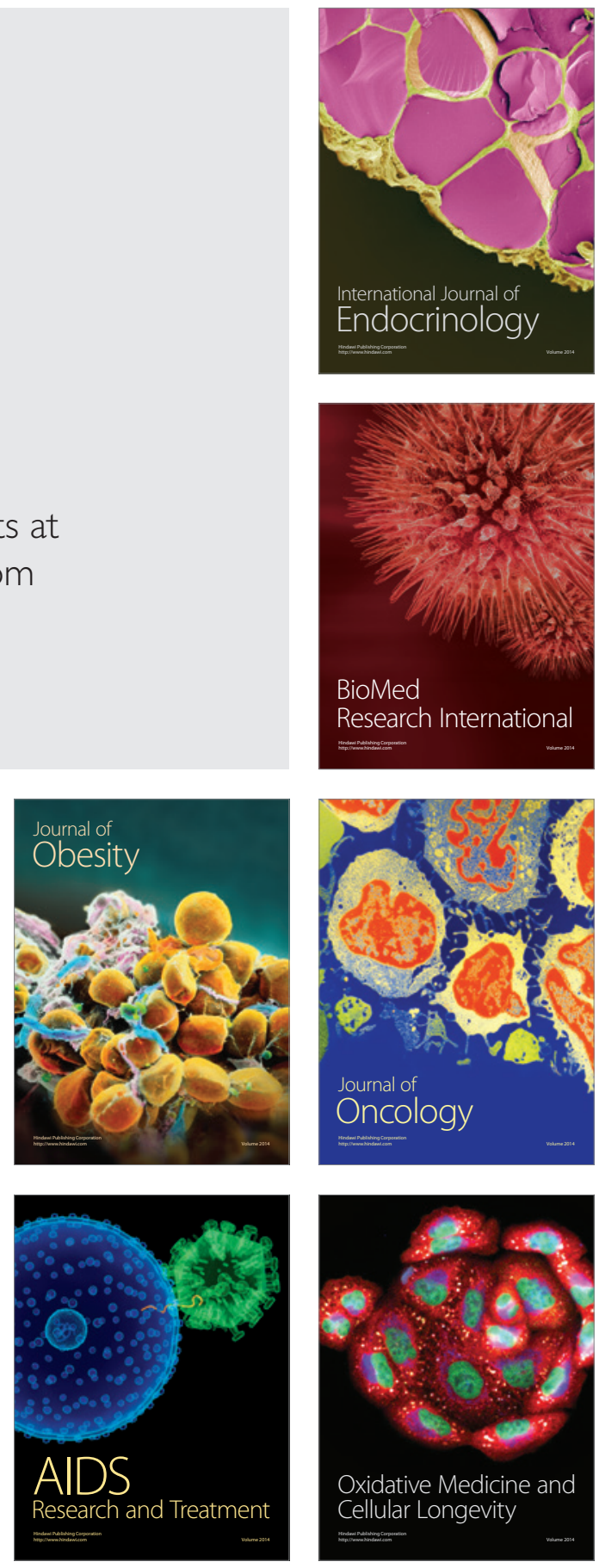